Portland State University

PDXScholar

$5-1-1970$

\title{
An electromyographic comparison of muscle action potentials of listeners presented time-compressed and normal speech stimuli
}

Barbara S. Moon

Portland State University

Follow this and additional works at: https://pdxscholar.library.pdx.edu/open_access_etds Let us know how access to this document benefits you.

Recommended Citation

Moon, Barbara S., "An electromyographic comparison of muscle action potentials of listeners presented time-compressed and normal speech stimuli" (1970). Dissertations and Theses. Paper 682.

https://doi.org/10.15760/etd.682

This Thesis is brought to you for free and open access. It has been accepted for inclusion in Dissertations and Theses by an authorized administrator of PDXScholar. Please contact us if we can make this document more accessible: pdxscholar@pdx.edu. 
AN ABSTRACT OF THE THESIS OF Barbara S. Moon for the Master of Science in Speech presented May 18, 1970.

Title: An Electromyographic Comparison of Muscle Action Potentials of Listeners Presented Time-Compressed and Normal Speech Stimuli.

APPROVED BY MEMBERS OF THE THESIS COMMIT TEE:

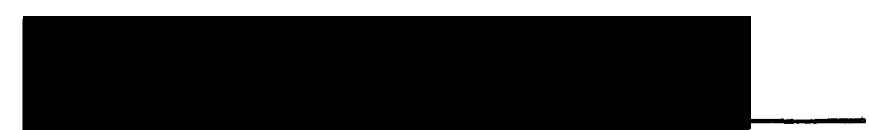
Patrick O. Marsh, Chairmąn

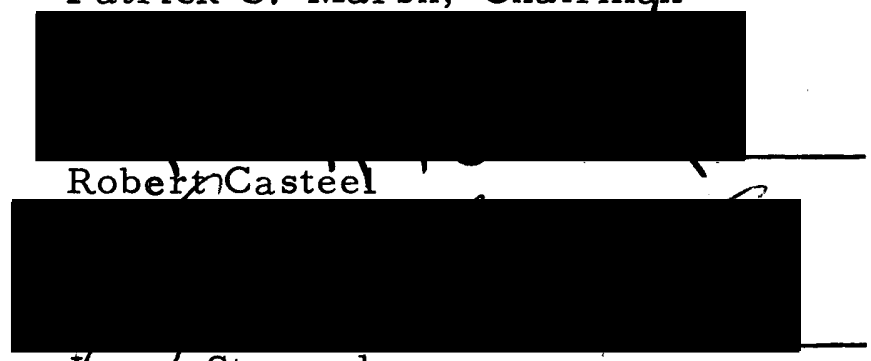

Larr/ Steward

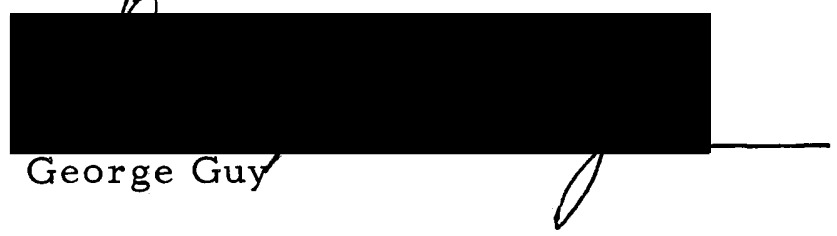

Speech compression is a method of electromyographically reducing the speech signal, resulting in a decrease in the time required for presentation of a message by increasing the number of words per minute. Research in the area of speech compression has to this time been focused on determining the listener response by means of 
comprehension testing. While comprehension testing uncovers the individual's ability to resolve, organize, and recall a message at accelerated rates, it gives no information about the listener's psychophysical response to compression. Does the individual find listening to compression to be tension-provoking or stressful? Or can a listener accommodate accelerated speech without stress?

The purpose of this study was to determine the individual's acceptance of compressed speech. "Acceptability" was operationally defined as finding no significant differences between tension levels produced while listening to normal speech rate as compared to tensions produced while listening to compressed speech rates. Tension levels were determined by an electromyograph which measures the amount of tension within a muscle.

The specific hypotheses researched were:

Hypothesis 1. Sampled muscular tension levels will differ significantly with Order of Presentation.

Hypothesis 2. Sampled muscular tension levels will differ significantly with Rate of Presentation.

Hypothesis 3. Sampled muscular tension levels will differ significantly between Males and Females.

Hypothesis 4. Sampled muscular tension levels will show significant interaction between Order of Presentation and Rate of Presentation. 
Hypothesis 5. Sampled muscular tension levels will show significant interaction between Order of Presentation and Sex of the Listener.

Hypothesis 6. Sampled muscular tension levels will show significant interaction between Rate of Presentation and Sex of the Listener.

Hypothesis 7. Sampled muscular tension levels will show significant interaction among Order of Presentation, Rate of Presentation, and Sex of the Listener.

A $6 \times 3 \times 2$ factorial design was constructed to examine muscular tension levels. The controlled factors were Order of Presentation, Rate of Presentation, and Sex of Listener. Rate of Presentation included three speech samples: normal (189 words per minute), speech compressed $25 \%$ ( 252 words per minute), speech compressed $50 \%$ ( 378 words per minute). These rates were arranged into six presentational patterns, composed of the three rates varied by its position within the sequence. Each Order of Presentation was presented to a male and a female listener, resulting in twelve subjects. The dependent variable was musculartension within the trapezius muscle produced by the listener as he heard the experimental presentation.

The sample was selected from speech students enrolled in 
Fundamentals of Speech at Portland State University, Winter Term, 1970.

Apparatus used to collect tension level readings were: bipolar surface electrodes, differential amplifier, oscilloscope, stereo tape recorder, and multi-functioned voltmeter.

The muscle tension levels were analyzed statistically by the three-factor analysis of variance test for significance. The finding of no significant differences at the .05 level of confidence for any of the experimental conditions warranted rejection of the research hypotheses.

The conclusion drawn from this finding was that compression within the limits used in this study is an acceptable mode of presentation based on the criterion that tension levels produced by compression differ only by chance from tension produced while listening to normal speech. It seems feasible, therefore, to substitute compression for normal speech in conditions where usage would be desirable. 
AN ELECTROMYOGRAPHIC COMPARISON OF MUSCLE

ACTION POTENTIALS OF LISTENERS PRESENTED

TIME-COMPRESSED AND NORMAL

SPEECH STIMULI

by

BARBARA S. MOQN

A thesis submitted in partial fulfillment of the requirements for the degree of

MASTER OF SCIENCE

in

SPEECH

Portland State University

1970 
TO THE OFFICE OF GRADUATE STUDIES:

The members of the Committee approve the thesis of Barbara S. Moon presented May 18, 1970.

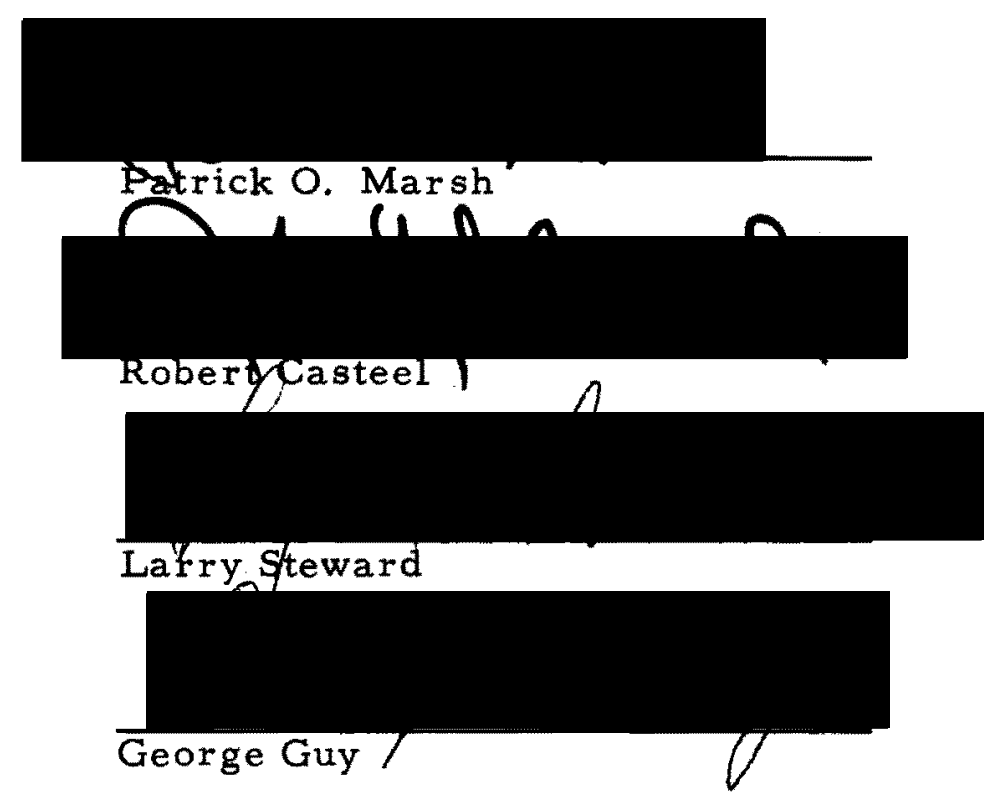

APPROVED:

Patrick O. Marsh, Robert Casteel, Co-chairmen, Department of Speech

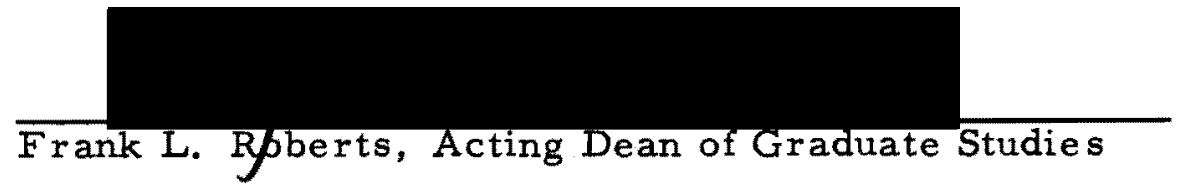

May 20, 1970 


\section{ACKNOW LEDGMENTS}

It seems only apprapriate to acknowledge those who lent their assistance so freely in the conception and development of the study. I am especially indebted to Dr. Patrick Marsh, my chairman, who directed me to the experimental problem and design, and to Dr. Robert Rinehart, who by giving so generously of his time, assistance, and assurance presented to me the theory, electronic background, and practice of electromyography. Without the technical assistance lent by these men, the study could not have been undertaken.

I wish, also, to extend my gratefulness to Eugene Whitley who directed my use of the computer for data analysis, and Ernie Klostermann who helped me solve the electronic crises I encountered. 
TABLE OF CONTENTS

PAGE

ACKNOW LEDGMENTS . . . . . . . . . . . . . . i iii

LIST OF TABLES $\ldots \ldots \ldots \ldots \ldots \ldots \ldots \ldots \ldots \ldots \ldots$

LIST OF FIGURES $\ldots \ldots \ldots \ldots \ldots \ldots \ldots \ldots \ldots \ldots \ldots \ldots$ viii

CHAPTER

I THE PROBLEM. .............. 1

Background $\ldots \ldots \ldots \ldots \ldots \ldots \ldots$

Statement of the Problem ......... 3

Definition of Terms........... 4

Limitations .................. 6

II REVIEW OF THE LITERATURE ....... 11

A Review of the Literature of Speech

Compression .............

Stimulus Variables: Compression

Organism Variables: The Listener

Response Variables: Listener Response

Conclusions ................ 28

III DESIGN OF THE STUDY .......... 30

Research Design............ 30

Rate of Presentation

Order of Presentation

Sex of Listener 
Hypotheses $\ldots \ldots \ldots \ldots$

Primary Hypotheses

Subhypotheses

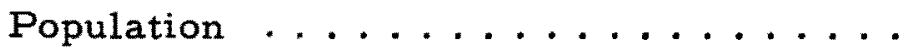

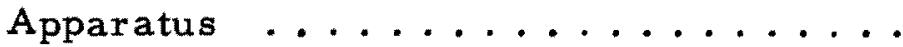

Stimulus Presentation

Recording Apparatus

Mea suring Apparatus

Procedures................

Pre-test Procedures

Testing

Post-test Procedures

IV $\quad$ FINDINGS $\ldots \ldots \ldots \ldots \ldots$

V SUMMARY AND CONCLUSIONS .........

Summary of the Findings.........

Primary Hypotheses

Subhypotheses

Suggestions for Further Research.....

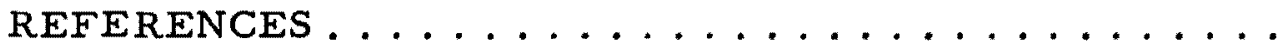

APPENDIX

A Form Sent to Students Composed of Invitation to Participate, Questionnaire, and Human

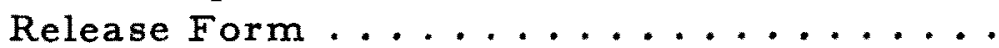

B "The Ten Worst Listening Faults" by Ralph Nichols...................

C Nichols' Comprehension Test ......... 


\section{LIST OF TABLES}

\section{TABLE}

PAGE

I Variables Influencing Reception of Compressed

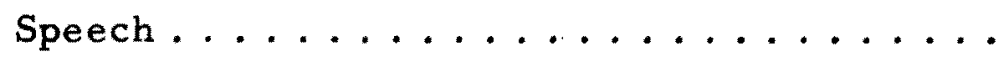

II Orders of Presentation of Speech Stimulus .....

III Sampled Muscular Tension Averages Within

$$
\begin{aligned}
& \text { Unreplicated Factorial Cells Measured }
\end{aligned}
$$

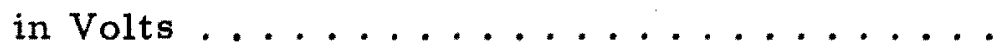

IV Three-Factor Analysis of Variance Test ......

V Mean Muscular Tension Levels for Order of

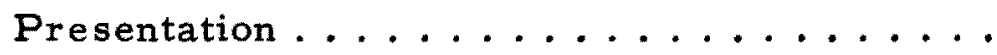

VI Mean Muscular Tension Levels for Rate of

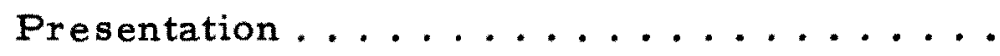

VII Mean Muscular Tension Levels Occurring for

the Interaction Between Order of Presen-

tation and Rate of Presentation.........

VIII Mean Muscular Tension Levels for Interaction

Between Order of Presentation and Sex

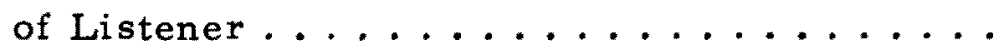




\section{LIST OF FIGURES}

FIGURE

PAGE

1 Listening Arrangements for Compressed

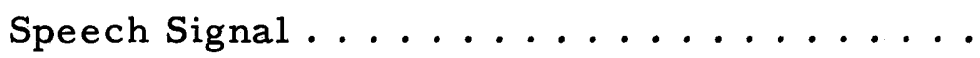

2 The Experimental Circuit Used to Collect

Electromyographic Readings from Subjects

Listening to Speech Stimuli .........

3 Standard Electrode Placement on Trapezius .... 
CHAPTER I

\section{THE PROBLEM}

\section{BACKGROUND}

It has been estimated that over $50 \%$ of elementary school class time and almost $90 \%$ of high school and college class time is spent listening (64). It is, then, startling to discover that listening to verbal material is considered an inefficient method of learning; that is, the rate at which people can assimilate material is more rapid than the rate at which it is usually presented in spoken form. This inequity between the assimilation rate of the listener and the rate at which words are spoken has motivated investigators to develop more efficient methods of using presentation time. Recently, a technique has been developed which decreases the amount of presentation time needed for a message by increasing the word-per-minute rate. This technique, speech compression, electromechanically samples small segments of recorded speech and automatically discards every other one. The remaining portions are reunited into a continuous flowing unit in which no original speech phoneme is completely discarded. The result is an increase in presentation rate with a decrease in presentation time. The pitch and quality aspects of the original 
message remain relatively free of distortion.

The speech compressor appears to have limitless applications as an educational medium to increase the amount of content that may be presented within a time period. Compression has potential use as a factor in message design. Messages can be clarified organizationally by use of compressed speech. For example, the main points of a message may be emphasized by use of normal speech with amplifications and summaries delineated by compressed speech. Compressed resumés can be placed intermittently throughout a message to aid listener retention. Theoretically, then, compression may offer a new dimension to time-management of messages. However, before compressed speech can be applied as an educational medium or as a factor in message design more must be discovered about the listener's acceptance of compressed speech. "Acceptability" in the sense used in the study refers to the individual's ability to receive compressed speech without manifesting tensions of a level significantly different from tensions produced while listening to normal speech.

To this time research in compressed speech has been limited to indirect observation of subject response by comprehension testing over the content of the compressed presentation. While this knowledge shows that certain degrees of compression are intelligible and temporally resolvable by the listener, it says nothing about the 
acceptability of compression to the individual. How does the listener physically respond to compressed presentations? Is it easily acceptable to him or does the increased pressure to resolve the accelerated auditory input produce stress or tension? Is the individual's tension level affected by presentations that employ various rates of compression?

The assumption underlying the research is that acceptability of compression can be determined operationally. By comparing the amount of tension produced by the individual while listening to normal speech with the amount of tension produced by the individual listening to compressed speech, it may be possible to determine if listening to compressed speech is as acceptable as listening to normal speech. Procedurally the comparison may be made by examining electromyographic readings of the amount of muscle tension produced while listening to normal and to compressed speech. Muscle tension levels are manifestations of the psychological tension felt by the individuals $(1,38,66)$ and may therefore be used an indicators of an individual's acceptance of compression.

\section{STATEMENT OF THE PROBLEM}

The problem to be researched is: What is the effect of compressed speech on listener muscle tension levels? The effect will be determined by observing the role of (1) Rate of Presentation, 
(2) Order of Presentation, and (3) the interaction between Rate and Order of Presentation on listener muscle response. Sex of the Listener will be examined to determine its effect on tension levels in interactions with the three conditions mentioned previously. A discussion of the variables of Rate, Order, and Sex of the Listener is presented to demonstrate why they are selected for study.

Rate of Presentation, which has three levels--normal, 75\% normal, and 50\% normal--is controlled to examine muscle tension differences due to rate. Order of Presentation, which has six levels composed of various sequencing of the three rates, is manipulated to discover whether particular patterns of presentation are more or less tension producing than others. The interaction between the two variables of Rate and Order is analyzed to determine if the position of a given rate within an Order significantly influences the listener's tension response for that rate. Sex of the Listener is controlled for observation since the effect of sex differences on tension levels has not been studied. In theory there is the possibility that tension response might be different for each sex. Since the role of Sex as an intervening variable is unknown, it will be observed.

\section{DEFINITION OF TERMS}

Several technical terms are used to define the research problem. In order to specify they way these terms are used within the study, they will be defined in this section. 
1. Acceptance of compression. Acceptance of compresion refers to the individual's ability to receive compression without manifesting tensions of a level that is significantly different from tension levels at normal speech rate.

2. Compressed speech. Compressed speech is speech which has been electromechanically altered, reducing the time of presentation by increasing the number of words per minute. Within this study speech was compressed to two levels: $75 \%$ normal speech time, and 50\% normal speech time. The word-per-minute ratios for the two compressed versions are 252 words per minute and 378 words per minute respectively.

3. Electromyography. Electromyography is a psychophysical testing instrument which amplifies and records the electrical impulse produced by muscle contraction.

4. Muscle tension levels. Muscle tension levels refer to states of contraction within skeletal muscles. Muscle tension level is thought to indicate the level of arousal, stress or tension felt by a person $(66,38)$. The terms "muscular tension levels," "muscular action potentials," "tension, "tension levels" and "muscle tension" are used interchangeably,

5. Normal speech. Normal speech in compression research is considered to be speech at the rate it was spoken that has not been mechanically altered in the time dimension. Generally, normal 
speech is considered to be between the range of 125 to 190 words per minute. Within this study normal speech is used to indicate the uncompressed version of the speech stimulus which is delivered at a rate of 189 words per minute.

\section{LIMITATIONS}

This section will offer a discussion of two types of limitations of the study: design and experimental. Design limitations are restrictions placed on the range of phenomenon being observed by choice of experimental variables. Limitations of design include the choice of testing instrument, speech stimulus, and population. Experimental limitations qualify the conclusions to be made by the study. A discussion of experimental limitations will amplify the restricting aspects of the laboratory setting and procedure.

The choice of testing instrument limited the phenomenon being observed. Since the research purpose was to observe an individual's tension response to normal and compressed speech stimuli, a testing instrument which would present quantifiable observations was needed. Electromyography was chosen for two reasons: first, electromyography measures muscular activity produced in an individual, and muscular activity is an indicant of tension or stress felt by the individual $(38,66)$; second, electromyographic readings offer a basis for comparing muscle tension levels. Further limitation of 
observation occurred with the selection of placement sites for electromyographic electrodes. This study is confined to observing the trapezius response in subjects. The trapezius was chosen because it is considered to be the best indicator of the general tension level of the individual (66, p. 173).

Choice of speech stimulus limited the observations to be made. Rates of 189 words per minute (wpm), 252 wpm, and 378 wpm were used because these are readily available. These rates, as shown from experimental findings in the area of comprehension of compression $(11,12,13,18,20,22,28,35,50,57)$, produce comprehension scores of high levels for rates within the range of $189 \mathrm{wpm}$ and 252 wpm with comprehension scores declining significantly at 378 wpm. Inclusion of these rates allows data to be collected within the range of rates known to produce both high and low levels of comprehension. Not included in the study are highly accelerated rates of speech or rates of speech belonging within the lower ranges of normal. Therefore, observations were limited to muscular response for speech rates of 189 wpm, $252 \mathrm{wpm}$, and $378 \mathrm{wpm}$.

The selection of a sample placed further limitation on observations. The population chosen were students enrolled in Fundamentals of Speech at Portland State University, Winter Term, 1970. This population was sampled because of availability. Subjects sampled were chosen on the bases of their age, naivete to compressed speech 
and the speech stimulus, freedom from use of drugs serving as muscular relaxants or stimulants, and fluency in English. The stipulations and the limits they place on the sample will be discussed.

Age was controlled because it is believed that the amount of muscular tonus, physical condition, response time and intensity would be similar for young adults between eighteen and twenty-five. Also, it is assumed that tension data would be more apt to reflect response to speech stimulus rather than individual differences if subjects were homogeneous with respect to age. Naĩvete to compression and to the speech stimuli was controlled to equalize as closely as possible the subjects' exposure to the speech stimulus. Studies have shown that practice in listening to compression has been accompanied by improved comprehension in some cases $(52,61$, 62). Therefore, lack of experience in listening to compression was stipulated since it appears to change an individual's reception. Individuals were screened for the possibility that they might have heard previously the speech used experimentally. Control of the exposure to compressed speech and the speech stimulus was imposed to insure equal experience of subjects with the speech stimulus. Subjects were requested to refrain from the use of drugs serving as either a relaxant or stimulant, since these drugs place individuals in artificial tension states and would invalidate experimental readings. Fluency in English was stipulated of subjects to equalize the 
difficulty of the listening situation.

The size of the experimental sample was limited to twelve individuals. The number twelve was chosen because it allows for one observation in each factorial cell produced by the design. To have used more subjects would have required increasing subject number to twenty-four to allow for two observations in each cell. This would have extended the amount of data to be analyzed and the amount of time needed beyond the feasible scope of the study.

Design limitations which have focused the type of experimental observations to be made included choice of testing instrument, stimulus rates, and subject selection. The testing instrument narrowed observations to the tension level produced by the trapezius muscle. Stimulus selection confined observations to muscular tension produced by speech at rates of $189 \mathrm{wpm}, 252 \mathrm{wpm}$, and 378 wpm. The population sampled restricted observations to students, enrolled in elementary speech classes, during Winter Term, 1970, at Portland State University. Further screening of subjects was performed to equalize factors which could potentially intervene with data to be collected.

A second type of limitation is produced by the experimental situation and procedures. Muscle tension levels were the variable being observed, and there are several factors inherent in the situation which could have affected tension levels. The laboratory, being 
an unnatural setting, could be tension-provoking to some individuals. The experimental procedure required the removal of garments to free the upper back area. Secondly, electrodes were placed on the upper back of the subject. This attachment involved personal contact with the experimenter which may have been stressful. These are conditions which might have produced tension within subjects. Precautions were taken to equalize these conditions by using standardized procedures to produce similar setting for each subject. Also, the purpose and method used were explained as thoroughly as possible in order to remove uncertainty from the situation. Factors of the laboratory setting, electrode placement and awareness of the experimental purposes were intervening variables which might influence tension response. Conclusions drawn from the study should be made with the se limitations in mind.

A discussion of the limiting factors influencing the study has been presented. Limitations considered were of two types, design and experimental. The purpose of discussing design limitations was to define as accurately as possible the phenomenon to be observed within the study. Experimental limitations indicated the nature of the qualifications to be placed on the conclusions to be drawn by the study. 


\section{CHAPTER II}

\section{REVIEW OF THE LITERATURE}

This chapter will review the experimental literature which has considered the effects of compressed speech on listeners. The purpose of the review is twofold: first, to offer an organized summary of the findings in the area of speech compression; and second, by this summary to give clarity and perspective to the experimental hypotheses of the study.

\section{A REVIEW OF THE LITERATURE OF SPEECH COMPRESSION}

Studies in the area of speech compression show that acceleration of speech to rates of approximately twice normal speed shows little loss in comprehension of subject matter by the listener. The phenomenon of reception of compressed messages has been researched isolating several variables which affect the compressed speech listening situation. These variables will be examined to determine their influence on the reception of compression. Table I outlines and classifies the variables that will be considered in review according to types as being either stimulus, organism, or response variables. Stimulus variables are those elements which are 
TABLE I

VARIABLES INFLUENCING RECEPTION OF COMPRESSED SPEECH

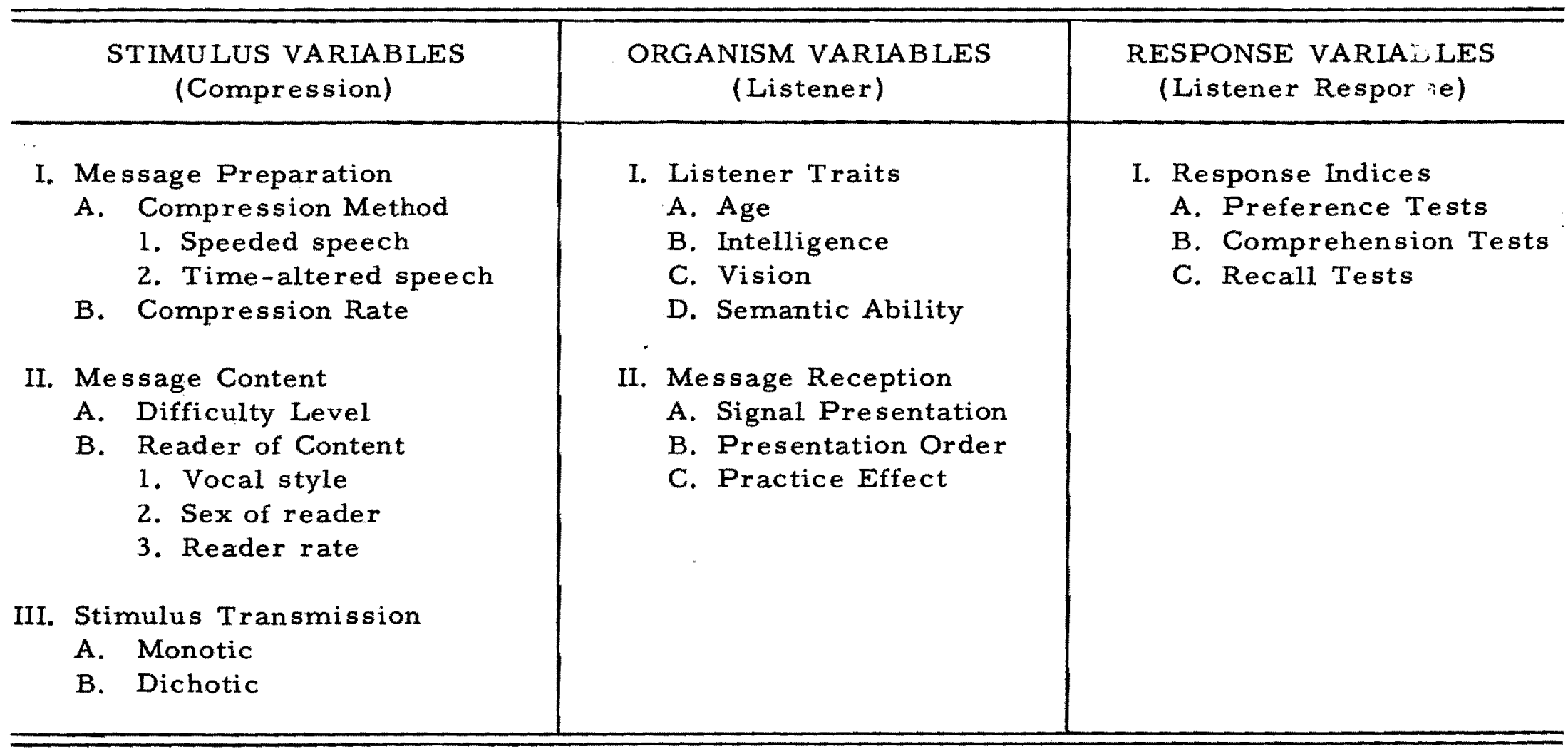


concerned with the preparation for compression and the technique of compressing a speech message. Organismvariables concern the characteristics or treatment of speech compression listeners. Response variables are tests or measurements which indicate a listener's response to compression.

\section{Stimulus Variables: Compression}

Speech compression is a process of selecting and retaining only partial segments of the speech signal. Research leading to the development of a method of compression came from individuals isolating some properties of the speech signal which aided perception of that signal. Miller and Licklider (44) offered a key study leading to the development of a speech compressor. By studying the articulation of spoken, phonetically balanced words under various conditions of interruption, they found intelligibility to remain even with considerable loss of the original stimulus word. Miller (43) stated that speech contains an abundance of discriminatory informational cues, indeed, far more than are needed by the listener. Pertaining to this excess he claims that signal reduction in various degrees can be accomplished without impairing intelligibility. Garvey (25) reasoned from these findings that it would be possible to physically delete small sections of recorded speech and join together the remaining segments, thus compressing the total time of the original speech 
sample, but simultaneously maintaining the original pitch and quality aspects of the signal. Using this method Garvey compressed speech to rates two and one-half times normal rate without loss of more than $20 \%$ intelligibility. Fairbanks, Everitt, and Jaeger (10) developed an electronic device that repeated the efforts of Garvey. The machine they developed is preset at an interval which selectively samples the recorded signal. In this form the instrument accepts the recorded signal, scans it at the desired speed, reproduces some segments and discards others. The parts of the signal which have been reproduced are then played together into a continuous unit, thereby compressing the original signal.

After the development of the se modes of compression several studies followed comparing time-compression with speeded-speech. Speeded-speech is speech played at a rate faster than it was originally recorded with pitch and quality aspects being distorted. Timecompressed speech is mechanically altered speech reduced in time with no pitch or quality alteration. McLain $(41)$ and Foulke $(15,18)$ compared speeded-speech with time-compressed speech by comprehension testing. McLain (41) found that subjects hearing timecompressed speech maintained a higher level of comprehension than listeners of the speeded version. Foulke (18) using similar stimuli found that subjects favored the time-compressed method and that comprehension test scores were higher with compression. Foulke 
(15) in a later study in this area found that comprehension was more dependent on word rate than on the method of compression, in fact, the method of compression was found not to be significant.

Research continued in the area of improving the techniques of speech compression. Scott (58) reported that by use of a hybrid computer he had simulated Fairbanks' (10) method of speech compression. Reasoning that with time-adjustment the message would be better received if the information that had been previously discarded by the Fairbanks method could be saved and used, Scott developed the dichotic method of signal presentation. In this method the odd-numbered segments are sent to one ear while the previously discarded or the even-numbered segments are sent to the other ear, resulting in two separate signals. By running a simple preference test on subjects Scott (58) determined that subjects chose the binaural presentation over the monaural presentation at more accelerated rates of presentation. Gerber (27) continuing in a similar vein analyzed that the methods of dichotic and monotic presentations were not the only methods of presenting compressed speech. He reasoned that there are two variables present: the signal produced by compression method and the signal received by the listener. The signal produced by compression could be varied monotically (Fairbanks method) or dichotically (Scott method). The signal received by the listener can be varied by the use of ears as being monotic (one ear 
involved), diotic (both ears involved) or dichotic (each ear receives a different signal).

By manipulation of these variables Gerber (27) devised four modes of presentation: dichotic signal and monotic listening where there are two different signals sent to one ear; unitary signal and diotic listening where one signal is sent to both ear; dichotic signal and diotic listening where the two signals go simultaneously to both ears; dichotic signal and dichotic listening where there are two signals, one going to each ear (See Figure 1). In testing the effectiveness (based on intelligibility tests) of the presentational methods Gerber found that the intelligibility relationship between the dichotomized speech signal and the listening signal was improved if the listening was also dichotomized.

Research in techniques of compression has been based on studies which show that words can be reduced temporally without significant loss in intelligibility $(43,44,25)$. The first mechanical time-compressor was developed by Garvey (25) which was reproduced electronically by Fairbanks, Everitt, and Jaeger (10). Scott (58) elaborated compression techniques by utilizing a hybrid computer to time-compress words. Scott (58) and Gerber (27) classified various transmission and listening conditions of monotic and dichotic presentations and initiated research into determining the efficiency of various presentational methods of time-compression. 


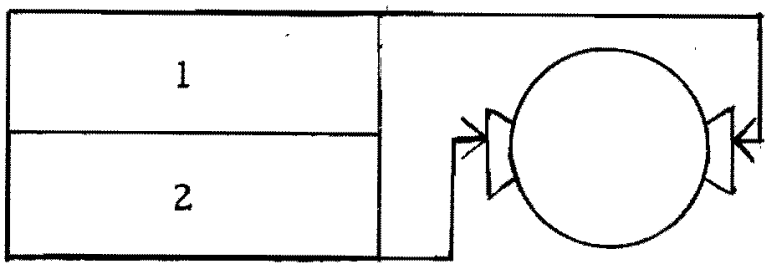

A. Dichotic signal, dichotic listening (where one signal goes to each ear).

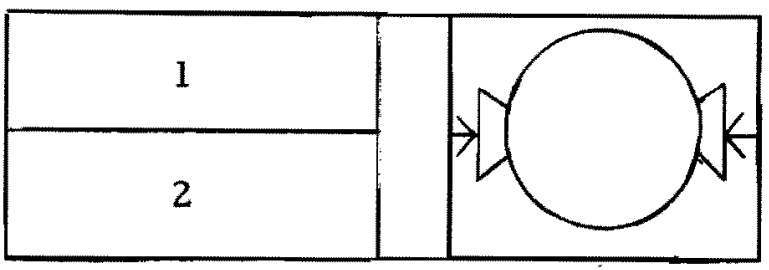

B. Dichotic signal, diotic listening (where both signals go to both ears).

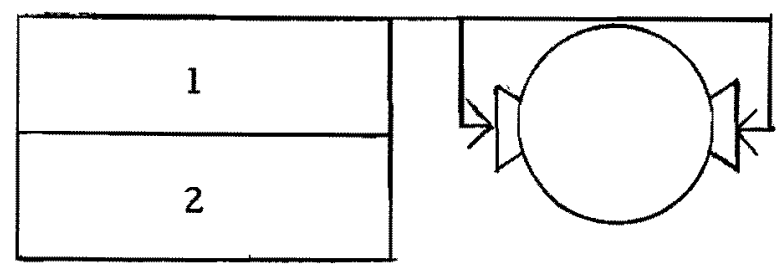

C. Unitary signal, diotic listening (where one signal goes to both ears).

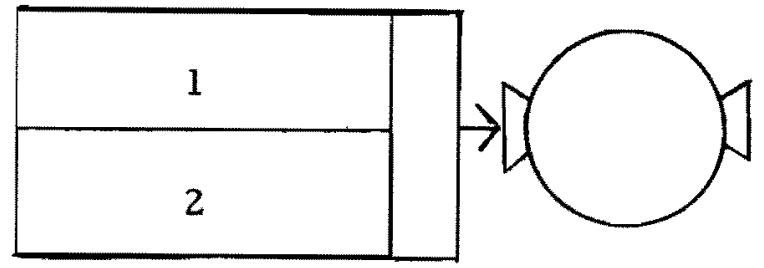

D. Dichotic signal, monotic listening (where both signals go to one ear).

Figure 1. Listening arrangements for compressed speech signal $(27$, p. 326).

Compressing a message involves choosing a compression method and a rate of compression. Rate is a time dimension. Speech compressors are set at a sampling interval which reduces the message on a percentage basis. For example, a five minute message reduced to $50 \%$ compression results in a two minute and thirty second message. Most studies measure rates of compression 
in words-per-minute (wpm). Normal speech is considered in compression studies to be any uncompressed rate of speech. Generally speaking normal speech is the range of approximately 125 to 190 wpm. Compressed speech rate is the percentage interval at which the speech compressor is set. For instance, a five minute message of 125 wpm when set at $50 \%$ reduction, becomes a 250 wpm message at two minutes and thirty seconds. Studies in compression have almost invariably used rates within a range of 125 to $475 \mathrm{wpm}$. Since this variable is a controlled variable that is generally used to observe comprehension, specific rates of compression and their ef fects on comprehension will be presented in the discussion of comprehension.

The second area of stimulus preparation is message content. Message content has been varied by: content difficulty, reader selection, and pause deletion techniques.

Content difficulty was found by Fairbanks, Guttman, and Miron (12) to influence comprehension of compressed messages. Foulke, Amster, Nolan, and Bixler (22) studied the efficiency of grade school braille readers to comprehend compressed speech passages and found that the difficulty level of the content presented was an important factor influencing comprehension. Goldhaber and Weaver (28) reported that comprehension was nonlinearly related to difficulty level of material. Reid (56) investigated the effect of rate of 
presentation on compression materials differing in grammatical complexity. Grammatical complexity was varied by simplifying portions of the Nelson-Denny Reading Test, and then compressing both the original and simplified versions. The simplified versions resulted in higher average comprehension test scores than the original more grammatically complex version.

Investigating the effects of reader voice and style of reading on passages to be compressed, Foulke (17) found that reader choice does influence comprehension test scores. Miron and Brown (45) manipulated talker rate, selective pause compressions, and random pause deletions finding that talker rate influenced the reception of compressed speech and that some selective pause compressions resulted in better comprehension test scores than material compressed utilizing random pause deletions.

The third area of stimulus variables found to effect compression reception is message transmission, which is the method of signal presentation. Gerber (27) has outlined various methods of signal transmission (see Figure 1, p. 17), and has initiated testing into this area. Initial investigations have shown that signals may be transmitted that are either monotic or dichotic and and that dichotomized speech signals are better received if listening is also dichotic. Scott (58) has added that dichotic signal transmission is preferred by subjects at high rates of compression. 
To briefly recapitulate, the stimulus variables of compression that affect reception of time-compressed messages are message preparation, message content, and signal transmission. Message preparation includes mode and rate of compression. Message content is concerned with content difficulty and reader characteristics. Signal transmission is the type of signal (monotic or dichotic) that is presented to the listener.

\section{Organism Variables: The Ligtener}

The recipients of time-altered messages are referred to as listeners. Experimentally, selection of listeners has often been controlled on the basis of common characteristics in order to test the listening performance of certain defined populations. Among characteristics being homogenized are age, aptitude levels, hearing acuity, vision, and listening ability.

In the area of aptitude Sticht $(60)$ reports a series of studies testing differences between reading and listening ability, performance on comprehension and intelligibility tests by using compression on listeners of high, average, or low mental aptitude. Results showed that comprehension performance of all aptitude groups declined as presentation rate increased and that lower aptitude subjects did not discriminate individually presented time-compressed words as well as higher aptitude subjects. Woodcock and Clark (65) 
evaluated the differences in comprehension test scores of elementary school children who were grouped according to intelligence. Lower intelligence subjects comprehended more at rates slower than the most efficient rates (ratio between time and comprehension) for higher intelligence subjects. Fairbanks, Guttman, and Miron (13) reported that listener aptitude affected factual comprehension significantly. Generally, studies agree that aptitude or intelligence influence reception of compressed messages.

Age as a variable shows influence on the very young and the very old in reception of time-compression. Wood (64) reports that grade level in elementary school children showed significance in children's ability to comprehend time-compressed speech. Studies by Pestalozzi and Shore (54) and Calearo and Lazzarone (8) determined that aged subjects had more difficulty or decreased ability to respond to accelerated word rates. Luterman, Welsh, and Melrose (40) studied the effect of compressed speech on three groups of males: aged, young hard-of-hearing, and normal young. Each group was found to have markedly different discriminatory abilities with performance for each group declining with compression rate increases. Conclusions from the studies dealing with age are cautioned in that research in this area has dealt with populations of the very old and very young in which discriminatory ability may be a stronger intervening variable than age. 
Foulke, Amster, Nolan and Bixler (22) began investigations into compressed speech as a learning aid for the blind. By comparing comprehension results between non-compressed and compressed speech, it was found that blind individuals, as do seeing individuals, have good comprehension of compressed speech at rates twice normal speaking time.

Friedman and Johnson (24) suggest that language factors and semantic ability of the listener are prime determiners of the individual's reception of compressed speech. They found from administering a battery of tests that the best predictor of comprehension at high rates of compression was the Best Trend Name Test, which was developed to measure the ability to evaluate semantic relations. This suggests that semantic ability influences comprehension of compressed speech.

Therefore, the aspects of aptitude, age, vision, and semantic ability are characteristics of the listener which have been investigated and found to influence reception of compression.

Besides isolating listeners on the basis of common characteristics, researchers have varied the types of aural experience presented to the listener. Aspects of listener message reception which have been varied are the type of signal transmitted to the listener, the order of presenting speech stimulus, and the allowance of practice-listening in compression. Most studies have utilized the 
Fairbanks method of signal presentation where one signal is presented to both ears, while the dichotic method used by Scott (58) and Gerber (27) has received little research. However, evidence was presented by Gerber (27) and Scott (58) suggesting that listening was improved if the signal presented to the listener was dichotomized at more accelerated rates of compression. Determining the advantages of modes of presentations is a new area of study, and requires further investigation before conclusions can be drawn.

Order of presentation, which is sequencing of the presentations of speech stimuli, has been researched by Fairbanks, Guttman, and Miron (12) who studied the effect of two consecutive redundant timecompressed presentations as compared to one presentation at half the speed. Their hypothesis that the redundant presentation should produce higher mean comprehension was supported. Reynolds (57) using six combinations of repeated auditory presentations indicated that four progressively slower presentations( 350 to $200 \mathrm{wpm}$ ) produced comprehension test scores higher than when the same number of presentations occupying the same total presentation time were made in either ascending order or when one rate was used consecutively four times. Jester and Travers (35) attempted to replicate the Reynolds study finding no variation of comprehension test scores for any presentation sequence used. The effect of various sequences of compression are left to be seen; however, evidence suggests that two 
consecutive redundant presentations at twice normal speed are better for comprehension than one at normal.speed.

The third aspect causing variety in the aural experience presented to listeners is the allowance of practice-listening to compressed speech. Orr, Friedman, and Williams (52), in a study designed to explore whether training with use of compressed speech could increase the individual's ability to comprehend compression, found that with the impact of practice subjects were able to develop greater proficiency in comprehension scores at high levels of speed (425 to $475 \mathrm{wpm}$ ). Voor and Miller (62) found improvement with five successive trials of listening to compressed speech at $380 \mathrm{wpm}$. In fact, comprehension scores reached optimum levels (level where significant improvement was obtained and maintained) after seven minutes of exposure to compression of prose material of average difficulty. Orr and Friedman (51) found that mean performance determined by comprehension test scores of subjects at $375 \mathrm{wpm}$ did improve with practice, so that it was not significantly different from comprehension performance at $175 \mathrm{wpm}$, after approximately five hours practice listening. Wood (64) found that among elementary school children practice was a significant variable affecting comprehension. Hence, research investigating practice-effect indicates that practice seems to have a positive influence on individuals' reception of compression even after relatively short exposure to 
time-compression.

Organism variables which have been manipulated in compression research are listener characteristics, which specify the population being examined, and the mode of exposing the listener to compression. Listener characteristics include age, intelligence, semantic abilities. Modes of exposure discussed were signal presentation, order of presentation, and allowance for practice-listening.

\section{Response Variables: Listener Response}

In order to determine how an organism responds under conditions of compression two methods have been currently employed. These are subjective preference tests and comprehension or recall tests.

Subjective preference is a condition in which listeners are able to choose or indicate what level of compression or method of compression they want to hear. Usage of subjective preference tests has been limited being reported by two researchers, Scott (58) and Orr (49). Orr (49) in examining self-pacing behavior of subjects indicates that when they were allowed to vary the rate of compression the average choice was approximately one and one-half times normal speech speed. Scott (58) reports that when subjects were offered a choice between monotic and dichotic presentational methods, dichotic was chosen more frequently for high levels of compression. 
The most common method of ascertaining a listener's response to compression is to test his comprehension of the material presented. Comprehension test scores are the most frequently used dependent variable in compression research. Fairbanks, Guttman, and Miron $(11,12,13)$ varying rates to $141 \mathrm{wpm}, 282 \mathrm{wpm}$, and $350 \mathrm{wpm}$ found that auditory presentations at $282 \mathrm{wpm}$ produced optimum efficiency of comprehension. (Optimum efficiency was determined by dividing comprehension test scores by time required for presentation among rates of compression known to be accompanied by high levels of comprehension.) Comprehension was reported as being $50 \%$ for $350 \mathrm{wpm}$, and $90 \%$ for $282 \mathrm{wpm}$. Foulke, Amster, Nolan, and Bixler (22) found comprehension to be affected slightly in the 225 to 275 wpm range, but to be affected markedly in the $375 \mathrm{wpm}$ range. Voor and Miller (62) determined that after five different trials of listening to compressed speech at $380 \mathrm{wpm}$ significant improvement in comprehension was attained. Orr, Friedman, and Williams (54) report that in their investigation increases in rate to $325 \mathrm{wpm}$ produced no significant loss in comprehension. Evidence presented by Wood (64) suggests that elementary school children hearing rates as high as $350 \mathrm{wpm}$ had $90 \%$ comprehension. Using listening aids of prècis and key-word charts along with messages compressed to $375 \mathrm{wpm}$, Or $\mathrm{r}$ and Friedman (51) found comprehension to be unimproved. Reynolds (57) observed that the order of presentation influenced comprehension 
test scores. This study was replicated by Jester and Travers (35) who did not confirm that order of presentation influenced comprehension. Barabasz (2) using lectures at normal and slightly compressed speeds reported no differences in recall test for either rate. Friedman and Johnson (24) observed that the best indicator of an individual's performance in comprehension of compression was the Best Trend Name Test which evaluates the ability to see semantic relations. Reid (56) found comprehension scores to be improved when subjects were given compressed messages simplified grammatically. He presented evidence that comprehension scores were approximately the same in the range of 175 to $325 \mathrm{wpm}$, falling off sharply between 325 to $375 \mathrm{wpm}$. Stricht $(60)$ found that subjects of high, average, and low intelligence performed most efficiently on a time and comprehension basis with speech rate of 275 wpm. Woodcock and Clark (65) observing the effect of compressed speech on elementary school children's comprehension, found that listening rates of 228 to $328 \mathrm{wpm}$ were more efficient for learning and retention than the normal rate of 178 wpm.

Some generalizations emerge from the review of compression literature concerning comprehension. Comprehension appears to be unaffected within the range of 175 to $325 \mathrm{wpm}$, beyond this point comprehension declines significantly. Reception of compressed speech is not the same for all individuals. Differences between 
individuals in areas such as aptitude or semantic ability can alter the reception of compression significantly. The success of listening to compression, measured by comprehension, depends on the interaction of several variables. Among the variables are the following: method of compression, rate of compression, difficulty level of content, reader of content, mode of stimulus presentation, listener traits, orders of presentation, and allowance for practice. Each of these factors have been found to have bearing on the comprehension of compressed messages.

The review of the literature has contained variables of three types: stimulus variables which deal with compression of speech samples, organism variables which concern the selection and experimental treatment of the listener, and response variables which determine the listeners' response to compression. The review is offered to organized the research findings in the area of compression in order to give perspective to the problem motivating this study. The following section will conclude the review by focusing the inquiry of the study in light of previous research in compression.

\section{CONCLUSIONS}

To this time researchers have focused their attention to determining the effectiveness of compression in terms of comprehension. If the question guiding research is how effective is speech 
compression as an alternative method in educational situations, or how effective is compressed speech for sending larger quantities of information in shorter times, it appears that other factors in conjunction with comprehension must be considered. One area requiring attention is assessing how compressed speech affects the listener: what happens to the organism in listening situations of compressed speech? Observation of usage of compressed speech within the classroom has presented comments from students claiming that they found the accelerated rates annoying, headache-provoking or distressing. They did not seem to find the listening experience comfortable or relaxing. It appears that if this method is being considered for usage as an educational medium, more must be known about the listeners' physiological response. This study purports to initiate this inquiry by exploring listener tension response to compressed speech by electromyography. Electromyographic technique will offer an index to how the listener responds to the stimuli of normal and compressed speech samples. By comparing the amount of tension produced by the trapezius muscle of the individual in the se lis tening conditions the response of the listener can be identified as to its effect on tension-production. This information coupled with the research of comprehension of compression should be useful in determining how and to what extend the listener can tolerate varied rates of compression. 
CHAPTER III

\section{DESIGN OF THE STUDY}

This chapter describes the experimental design of the study. It includes discussion of the following areas: research design, hypotheses, population, apparatus, and procedures.

\section{RESEARCH DESIGN}

The purpose of this study is to determine whether individuals listening to samples of speech at normal and compressed rates exhibit differences in muscular tension levels for any of the se rates. To specify the area of interest more thoroughly the following concepts will be defined operationally: normal speech rate, compressed speech rate, muscular tension levels, and electromyographic technique.

Normal speech rate is defined as the rate at which the original speech was actually delivered by the speaker, measured in words per minute (wpm). Compressed speech rate is that rate which is produced by mechanically modifying the original speech rate by accelerating the number of words per minute, reducing the total time of the message without reducing pitch or quality aspects of the 
speech signal. Muscular tension level or muscular action potentials (MAPs) are electrical impulses produced by a muscle in states of tension which may be detected and measured by electromyographic techniques. Electromyography is a system for amplifying and recording the electrical impulses produced by muscular activity.

In order to determine whether tension differences exist when a person is presented speech samples of normal and compressed rate an experimental design, factorial in nature, was constructed. The experimentally manipulated factors for this study are of three classes: Rate of Presentation of speech stimulus, Order of Presentation, and Sex of Listener.

\section{Rate of Presentation}

The factor of Rate of Presentation was varied to produce three samples of speech. This was accomplished by taking a portion of "The Ten Worst Listening Faults," a speech delivered by Ralph Nichols at a rate of $189 \mathrm{wpm}$, and compressing it by means of a Varivox Rate Changer. The first compression transformed the original signal to a rate of 252 words per minute, a $25 \%$ reduction of the original message time. The second compression transformed the original signal to $50 \%$ message time, resulting in a 378 words per minute presentation. Thus, Rate of Presentation has three levels: 189 wpm (normal), $252 \mathrm{wpm}$ ( $75 \%$ normal), and $378 \mathrm{wpm}$ 
(50\% normal).

Order of Presentation

The second factor controlled experimentally is the Order of Presentation. Order of Presentation is defined as the sequence in which the three speech samples varied by rate are presented to the listener. An exhaustive list of the possible presentational patterns reveals six differing Orders of Presentation that were used experimentally (See Table II).

TABLE II

ORDERS OF PRESENTATION OF SPEECH STIMULUS

\begin{tabular}{llll}
\hline \hline & \multicolumn{3}{c}{ Sequence of Rates } \\
\cline { 2 - 4 } Order & \multicolumn{3}{c}{2} \\
\hline \\
Order A & normal & $75 \%$ normal & $50 \%$ normal \\
Order B & normal & $50 \%$ normal & $75 \%$ normal \\
Order C & $75 \%$ normal & normal & $50 \%$ normal \\
Order D & $75 \%$ normal & $50 \%$ normal & normal \\
Order E & $50 \%$ normal & normal & $75 \%$ normal \\
Order $\mathrm{F}$ & $50 \%$ normal & $75 \%$ normal & normal \\
\hline \hline
\end{tabular}

\section{Sex of Listener}

Each Order of Presentation was presented to two listeners, a male and a female, resulting in a sample of twelve listeners.

The dependent variable being sought by controlling the factors of Order of Presentation, Rate of Presentation and Sex of the 
Listener is the amount of electrical impulses produced by the trapezius muscle in listeners as they receive the experimental speech stimuli.

In summary, a $6 \times 3 \times 2$ factorial design with controlled variables of Order of Presentation, Rate of Presentation and Sex of Listeners was constructed with the ensuing muscle tension levels being the dependent variable sought.

\section{HYPOTHESES}

The general hypothesis of the study is that muscular tension levels will vary with the speech stimulus presented. Specific hypotheses are proposed in relation to interactions of factors presented in the experimental design. These will be divided into primary hypotheses with which the study is directly concerned and subhypotheses which are analyzed due to interactions within the factorial structure.

\section{Primary Hypotheses}

Hypothesis 1. Sampled muscular tension levels will differ significantly with Order of Presentation.

Order of Presentation is predicted to influence muscle tension levels. It is expected that presentations of rates in ascending order (189 wpm, 225 wpm, $378 \mathrm{wpm}$ ) will be less tension producing than 
rates in descending order (378 wpm, $225 \mathrm{wpm}, 189 \mathrm{wpm})$. The prediction is based on reports of Belanger (6) who indicated that the psychological difficulty of a task dictates the amount of tension an individual will produce. The more difficult the task, the greater the tension values will be that accompany the task. The task of listening to the presentation of descending rate values appears to be the most difficult listening situation for the following reasons. First, the amount of perception time allowed the listener is reduced in the first presentational sample $(378 \mathrm{wpm})$. Listening at this rate has been shown to result in reduced comprehension $(56,62,64,65)$. Due to loss of perception time and reduced comprehension, it is assumed that listening will be more difficult at $378 \mathrm{wpm}$ rate resulting in heightened tensions. Second, since the listener had significant loss of comprehension for the first presentation of the speech sample, it is predicted that he will listen attentively to the second speech sample. Attentive listening is reported to be accompanied by high tension levels by Murrell (47). The combined tension scores for the first and second speech samples in the presentational pattern of descending rate is predicted to produce tension scores that are significantly different than ascending rate scores. Speech samples in ascending rates are thought to produce less tension due to the redundancy of the presentational pattern. It is predicted that subject's initiation to the speech sample at normal rates will be accompanied by interest and attention, hence, high 
tension scores. The second speech sample in the presentation is predicted to produce lower tension levels since the subject has heard the content previously and his attention will probably have waned because of the redundancy. The third sample is thought to be accompanied by a slightly elevated tension response due to the novelty of hearing speech compressed at such an accelerated rate. However, after the initial response is made to the novelty, tensions are predicted to decrease due to lack of motivation to listen to the presentation for a third time. Therefore, significant differences in muscular tension are expected for varied presentation patterns of speech samples with the highest tensions manifested in the order of descending rates.

Hypothesis 2. Sampled muscular tension levels will differ significantly with Rate of Presentation.

Muscular tensions, it is predicted, will increase significantly for speech compressed at $378 \mathrm{wpm}$. This is hypothesized for the following reasons: first, subjective reports of students listening to compression have indicated that listening was difficult and that attentive listening, especially at $378 \mathrm{wpm}$, produced strain or headache sensation; experimental findings in the area of comprehension of compression have shown that comprehension falls off significantly at approximately 325 wpm $(56,62,65)$. Belanger $(6)$ has indicated that 
muscle tensions are a function of the psychological difficulty of a task. That is, the more difficult the task the greater the tension response. As indicated in the discussion of Hypothesis 1, speech at $378 \mathrm{wpm}$ is thought to increase the psychological difficulty of the listening task, since the perception time previously allowed the listener at normal rates has been drastically reduced (18). Students have reported finding listening to compression at the $378 \mathrm{wpm}$ level difficult, and the decline of comprehension would tend to indicate that the listening is more difficult at a rate of $378 \mathrm{wpm}$ than at normal rates. The predicted increase in difficulty of the listening situation will be manifest in high levels of muscle tension shown for the rate of 378 wpm.

Hypothesis 3. Rate of Presentation and Order of Presentation will show significant interaction.

Subjects introduced to the speech stimulus by hearing the highest rate of compression first will, it is believed, manifest higher tension levels than subjects hearing other presentations. Subjects hearing normal rate last in order of presentation, it is projected, will register the least level of muscle tension during that presentation. These predictions are based on information presented by Belanger (6), reviewed in previous hypotheses, that the harder the task the greater the tension level and, conversely, the easier the 
task the lower the tension level. It is suspected that subjects hearing the $50 \%$ normal rate of compression on their first exposure to the speech stimulus will find the listening task more difficult than subjects hearing either normal or $75 \%$ normal rates as their first exposure, and this increased difficulty will be manifest in higher tension levels. At the same time, it is believed that tension levels will be lowest for subjects hearing normal presentation speed as their last stimulus. Since they have heard the speech stimulus twice previously in more difficult listening situations, they will probably find the last listening situation unchallenging or boring, reflected in low levels of muscular tension. It is predicted, therefore, that Order of Presentation and Rate of Presentation will interact significantly influencing muscular tension rates.

\section{Subhypotheses}

The subhypotheses of the study involve the factor of Sex. To this time the effect of Sex on muscular reaction has been unstudied. Theoretically, there is the possibility that Sex is an intervening variable of importance in the reception of compression. It is possible that one sex accepts compression better than the other. Since the effect of Sex is unknown as to its effect in the reception of compression or in muscle tension response, it has been controlled for observation. Research centered around the subhypotheses is offered as an 
exploratory inquiry into the possibility of Sex influencing compression reception. The subhypotheses presented are the result of the factorial design showing main and interaction effect of Sex as a variable.

Subhypothesis 1. Sampled muscular tension levels will differ significantly between Males and Females.

Subhypothesis 2. Sampled muscular tension levels will show significant interaction between Order of Presentation and Sex of the Listener.

Subhypothesis 3. Sampled muscular tension levels will show significant interaction between Rate of Presentation and Sex of the Listener.

Subhypothesis 4. Sampled muscular tension levels will show significant interaction among the variables of Rate of Presentation, Order of Presentation, and Sex of the Listener.

\section{POPULATION}

The experimental sample was chosen from speech students, enrolled in Fundamentals of Speech during Winter Term, January 1970, at Portland State University. Two Fundamentals of Speech 
classes were eliminated from the sampling procedure because the enrollment for the classes was not randomized: these were special courses designed for individuals considered to have traits in common, such as reticence or underachievement. The population sampled contained five courses with an approximate enrollment of twenty-five persons apiece.

The following sampling procedure was used. Names of students were recorded under the name of their respective instructor. Each instructor was assigned a random number and ordered by that number. Each student in the order presented by going through the instructors' rosters sequentially was given a random number. From these numbers the students having the thirty lowest values were chosen to comprise the potential sample.

The experimental sample was screened by distributing a form letter, a questionnaire, and a release document (See Appendix A) to be completed by potential subjects. From the returned forms the sample was chosen based on the following criteria. Subjects were requested to be between the ages of eighteen and twenty-five, naive to compressed speech and the speech stimulus, free from use of drugs serving as muscle relaxants or stimulants, and fluent in English. These criteria were established to control conditions that 
might influence muscular tension readings. ${ }^{1}$ A final experimental sample of twelve persons was chosen, six Males and six Females, from individuals fulfilling the criteria listed.

\section{APPARATUS}

The theoretical aspects of the study have been detailed in previous sections of this chapter. This section includes a discussion of the instruments used to collect the experimental data. Three aspects will be included: stimulus preparation, recording apparatus, and measuring apparatus.

\section{Stimulus Preparation}

The experimental stimulus was a sample of a speech delivered by Ralph Nichols on "The Ten Worst Listening Faults" presented at 189 wpm (See Appendix B). The Nichols' tape was compressed by means of a Varivox Rate Changer to $75 \%$ and $50 \%$ its original time, resulting in three experimental rates of $189 \mathrm{wpm}, 252 \mathrm{wpm}$ and 378 wpm. The three Rates were then recorded into six differing presentational patterns (See Table II, p. 32) comprising the experimental Orders of Presentation.

Each Order of Presentation had a presentation time of fifty-six

${ }^{1}$ Further discussion of the criteria used to screen subjects is given within the Limitations section of Chapter I, pp. 7-9. 
minutes and thirty seconds. The time element is obtained by the following formula: Sample $1+$ thirty second pause time + Sample $2+$ thirty second pause time + Sample 3 , where the normal sample has a twenty-four minute and forty second presentation time, the $75 \%$ compressed version has an eighteen minute and thirty second presentation time, and the $50 \%$ compressed version has a twelve minute and twenty second presentation time.

The manipulation of Rate of Presentation and Order of Presentation resulted in the experimental speech stimuli.

\section{$\underline{\text { Recording Apparatus }}$}

The following equipment was used to collect muscular tension readings: bipolar surface electrodes, differential amplifier, oscilloscope, stereo tape recorder. Ancillary equipment used to give a simultaneously correlated record of the speech stimulus with muscular tension readings was a monaural tape recorder and a patchcord. Each of these instruments will be described in detail, beginning first with a general overview of the experimental circuit given visually in Figure 2 followed by an explanation.

Figure 2 depicts the seven basic steps employed in collecting the experimental data. First, the speech stimulus is presented by monaural tape recorder (1) to subject via headphones (2). Second, contact surface electrodes (3) located on the upper trapezius of the 


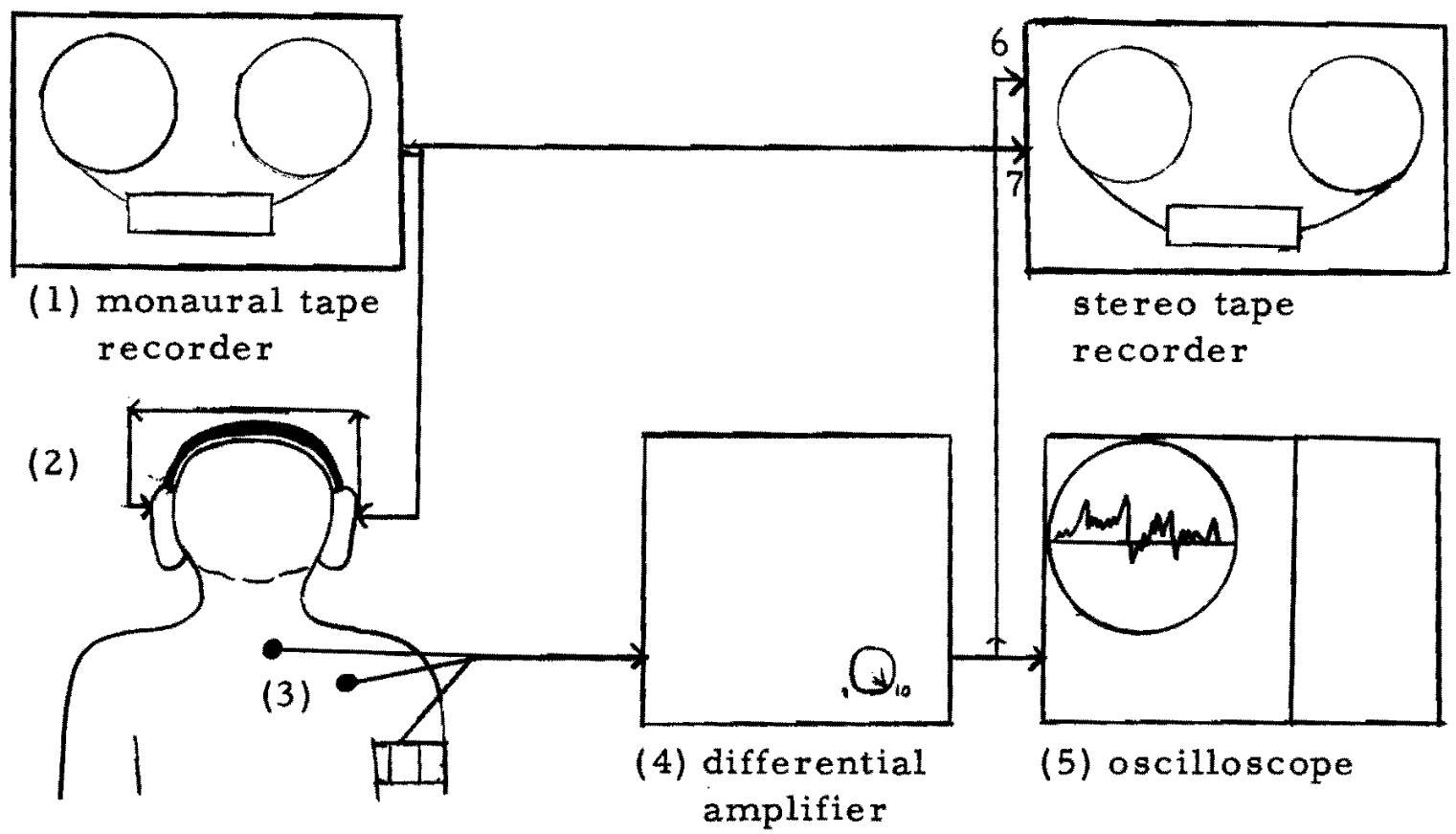

Figure 2. The experimental circuit used to collect electromyographic readings from subjects listening to speech stimuli.

subject pick up muscular activity while the ground wire attached to the subject cancels extraneous subject noise. This signal is carried to the differential amplifier (4) which cancels extraneous external noise and amplifies signal carrying this amplified signal to the oscilloscope (5) where the impulse may be seen on a cathode-ray screen. The amplified signal leaving the differential amplifier is also carried to channel 1 of a stereo tape recorder (6) where the signal is recorded on magnetic tape. While the muscular activity is being recorded on channel 1 of the stereo tape recorder the speech stimulus transmitted by the monaural tape recorder (1) is being carried via a patchcord into channel 2 (7) of the stereo tape recorder. 
This results in a simultaneously correlated recording of the speech signal received by the subjectwith the muscular tensions he produces. The following section will include a discussion of the instruments involved in gathering experimental data by describing their function, their specifications, and their projected accuracy.

Bipolar Surface Electrodes. The purpose of electrodes in psychological testing is to receive impulses from the subject and to allow these signals to be carried to some testing instrument. In this experiment where the method employed is electromyography the electrodes function specifically to pick up electrical impulses produced by the trapezius muscle in various states of tension and to allow these impulses to be transmitted to an amplifier.

Electrodes are characteristically chosen of the basis of the following criteria: low impedance and resistance, reliability, and innocuousness (1). Low impedance is achieved by using metals of high conductance such as silver or zinc applied to the skin with an electrolyte medium to produce a circuit (1, p. 16). Reliability is determined by uniform placement of electrodes on subjects and effectiveness of contact. Innocuousness is determined by the flexibility and lack of physical disturbance that the electrodes allow the subject (1, p. 17).

The electrodes used in this study were United States dimes composed of silver and copper. Burdick electrode paste was 
employed with the electrodes to establish a contact of low impedance and resistance. Reliability of electrodes was maintained by using standardized attachment procedures and by securing electrode contact with the skin of the subject with heavy tape. Since placement of electrodes consisted only of applying electrode paste and tape over the electrodes, contact was maximized while discomfort was minimized. Maintenance of electrode contact was assured by the experimenter who viewed an oscilloscope for wave changes which would indicate a los s of contact.

In conjunction with bipolar surface electrodes a metal ground was attached to the subject by means of an elastic band. The electrode paste was used between the skin of the subject and the metal of the ground to assure contact. The ground was employed for reduction of extraneous noise picked up by the electrodes.

Differential Amplifier. The electrodes carry electrical impulses to a differential amplifier where two events take place: first, common mode rejection of extraneous noise occurs, purifying muscular action potential impulses; and second, the impulses are amplified. The differential amplifier used in this experiment is a WestCon Differential Amplifier: Low Level, model 11, volts 120, frequency 60 with a 1 to 10 output gain. Its specifications are as follows: differential gain is $1.4 \times 10^{5}$, common mode gain is 1.2 , noise level at full gain is $1.5 \%$, and passband is 20 to 2 kilohertz \pm 3 decibels. 
Throughout the experiment full gain was employed.

Oscilloscope. The oscilloscope functioned in this experiment as a method of providing visual display of amplified muscular impulses. It was used by the experimenter to determine that electrodes maintained contact and that subjects were not making any bodily movements which could influence recorded data. The instrument used was a Tektronik Type 503 Cathode Ray Oscilloscope, which is a low-frequency, high sensitivity instrument providing accurate measurements in the range from DC to 450 kilohertz AC.

Stereo Tape Recorder. The stereo tape recorder functioned to record on magnetic tape the amplified muscular impulses while simultaneously recording the speech stimulus received by the subject. The stereo tape recorder thus provided by usage of two channel recording a simultaneously correlated recording of muscular activity as it corresponded to the speech stimulus. This was used by the experimenter to analyze muscular tension, and this allowed precision in determining when to begin measurement of tension by knowing when the subject began hearing the speech stimuli. The stereo tape recorder used in this experiment was a Sony TC-200. Specifications for this instrument are as follows: frequency response is $30 \sim$ 13,000 hertz at $3-3 / 4$ inches per second; level is controlled individually for both channels; inputs are of high and low variety with accommodation of input jack from $250 \sim 1 \mathrm{kilo}$ ohm impedance 
for low input; high impedance auxiliary inputs have sensitivity of 17 decibels (0.11 volts). The stereo tape recorder received input from the differential amplifier of high impedance into uxiliary input channel 1. It received low impedance input from microphone input channel 2 to record the speech signal. Scotch Magnetic Recording Tape was used.

Monaural Tape Recorder. The tape recorder which was used to transmit the speech signal to the subjects was a Sony-matic.

Measuring Apparatus

The electromyographic potentials recorded by the stereo tape recorder were analyzed by a Hewlett-Packard Multi-Function Meter, Model 3450A with True RMS Converter, model 11078A.

The Multi-Function Meter is a five digit integrating digital voltmeter with $A C$ functions added. The $A C$ function gives voltage measurement ranges of 1 volt, 10 volts, 100 volts, 1000 volts with $20 \%$ over range capability.

The voltmeter integrates voltage values for the muscle tension readings recorded on tape. which are the data used for statistical analysis.

\section{PROCEDURES}

In previous sections the theory and the experimental circuit employed in this study have been defined. This section reports the 
experimental procedures that were followed, and they will be discussed in three phases: pre-test, test, and post-test.

Pre-test Procedures

The pre-test phase of this experiment involved sampling procedures and subject orientation.

1. Students enrolled in Fundamentals of Speech, Winter Term, 1970, chosen by random sampling were requested to assist in this experiment. Those willing to participate were notified of the data and time they were to participate.

2. Upon arrival to the laboratory the subject was read the following explanation of procedures:

As you know you have been selected to participate in an experiment which involves listening to three samples of speech varied by rate. The purpose of this experiment is to discover whether listening to the se samples of speech produces any changes in your muscular tension response. We will test for tension changes by use of surface electrodes which will be attached to your trapezius muscles (as shown within the diagram). Your trapezius muscle is located in the general area between your shoulder blades, and to this muscle we will adhere two electrodes. The impulses of tension within your muscle will be picked up by these electrodes and amplified through this machine to be recorded on this tape recorder.

Your part in the experiment consists only of listening carefully to the speech samples which will be transmitted to you through the headphones. After the experiment a short quiz over the material will be given to you, and your responses to the listening experience will be requested.

In order to make you as comfortable as possible and to reduce outside distractions during the experiment you will lie on this bed and when the experiment commences you are 
requested to close your eyes.

You will hear three samples of speech which are the same except that the rate of presentation has been changed in each sample. There will be a thirty second pause between the speech samples, and the total listening time is 56 minutes. To review our procedure briefly, we have the following steps: (1) You will lie on the bed on your abdomen arms at your side: (2) I will place the electrodes on your upper back. (3) The speech samples will be played for you while you listen. (4) There will be three samples of speech separated by thirty second pauses. During the listening you are urged to lie as quietly as possible, so as not to disturb the electrodes: --this is very important. I will be here with you during the experiment to operate the machines.

Now, to facilitate attachment of the electrodes, would you remove your (-) and put on this robe backward, so that your back is free. I will step outside while you change into this robe; please notify me when you are ready.

After hearing the instructions the subject was permitted to question for clarity.

3. After changing into a robe the subject was requested to lie on a bed with his arms relaxed by his side, and his head turned to the right.

4. The following standarized electrode placement procedure was used to attach electrodes to the upper trapezius muscle of the subject:

a. Placement of the first electrode was accomplished by drawing a horizontal line running through the area between the spines of the first thoracic and the seventh cervical vertebrae. Then, a mark at the point 1-5/8 inch outward from the midline 
for placement of the center of the first electrode was made (38, p. 288).

b. This area was covered liberally with electrode paste which was massaged into the skin for approximately one minute. The electrode paste was also spread over the surface of the electrode which was to maintain contact with the skin.

c. The electrode was placed on the skin in the designated area and secured by three strips of white adhesive tape.

d. Placement of the second electrode was accomplished by drawing a horizontal line through the space between the spines of the second and third thoracic vertebrae to the posterior edge of head of the humerus. The center of the second electrode was placed on the point which lies mid-distance between the backbone and the posterior edge of the head of the humerus. This placement is one which shows visible strain when the head of the subject is moved down and to opposite sides (38, p. 289).

e. Application of electrode paste and adhesion of second electrode is the same procedure followed in steps b and c explained above.

f. When electrodes were in place they appeared as indicated in Figure 3.

5. Headphones were positioned on the subject and volume for reception of the speech signal was adjusted to be comfortable. 


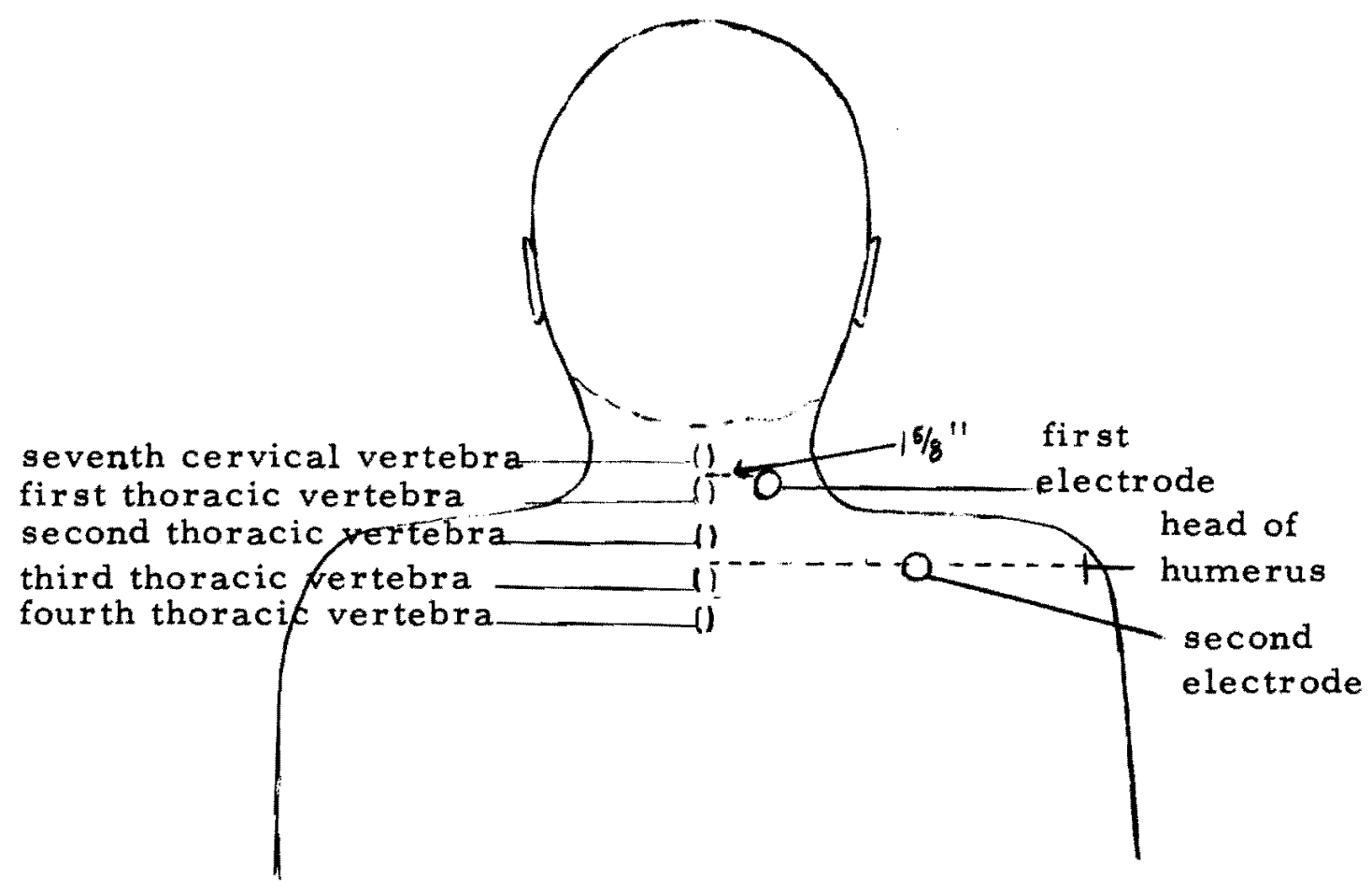

Figure 3. Standard electrode placement on trapezius.

6. The volume level at which muscle tensions were being recorded by the stereo tape recorder was written down for use in analyzing data.

7. The tape containing the speech stimulus was begun and the lights were turned off.

$\underline{\text { Testing Procedures }}$

Testing phase consisted of collecting the muscular activity data. 
1. Prior to subject's arrival to the laboratory the differential amplifier was set at full gain.

2. The order of presentation of speech stimulus was assigned to subject and recorded.

3. During the experiment the electrical activity of the trapezius muscle of the subject was recorded on magnetic tape for future analysis.

4. After the experiment a test requesting subjective feelings toward the situation and requesting recall of subject matter was presented to the subject (See Appendix C). This test was used as a motivational device, announced prior to the experiment to provide subjects with an equal reason to listen.

\section{Post-test Procedures}

1. The muscular tension levels recorded on tape were translated into numerical values through use of an integrating voltmeter by the following procedure:

a. The volume for playback of collected tension readings was set at twice the volume level at which it was recorded.

b. Each tape collected during the experiment from a subject was played on the stereo tape recorder with the output of channel 1 which contained amplified muscle impulses being connected to the integrative voltmeter, while channel 2 
containing the speech stimulus was played through a speaker.

c. When the first word of the speech signal began, the voltmeter was triggered and readings were recorded for each ensuing three second time period. The last reading recorded for each of the three speech samples was the reading that occurred either concurrently with the last word of the sample or shortly before if the next reading went beyond the last word. This procedure was followed for each of the three speech samples on the stimulus tapes.

d. The readings collected show the average root-meansample alternating current voltage produced by the upper trapezius muscle of subjects for a 2.7 time interval. Reading period was 2.7 seconds with 0.10 of a second required for integration. These readings were averaged to give a mean tension rate for each individual under the three conditions of rate. Therefore, each subject was given three readings showing his average tension level under the rates of normal, $75 \%$ normal, and $50 \%$ normal.

2. This data was interpreted statistically by a three-factor analysis of variance for a $6 \times 2 \times 3$ design. Statistical analysis was accomplished by CDC 3300 computer using the Oregon State University Statistical Analysis Program, OSU-03, which is a statistical model for a three-factor analysis of variance. 


\section{CHAPTER IV}

\section{FINDINGS}

The purpose of this chapter is to present the findings of the study. Each of the research hypotheses will be presented along with statistical interpretation. This chapter is limited to reporting findings, while Chapter $\mathrm{V}$ will summarize and interpret these findings.

The research hypotheses were analyzed by a three-factor analysis of variance test utilizing the $\underline{F}-$ ratio for significant determination. ${ }^{1}$ The criterion set for rejection of the null hypotheses is the conventional $p<.05$. Tables will be presented showing myographic observations gathered from subjects, analysis of variance, and means for various subgroups considered in testing effects. From these data, then, each hypothesis will be reviewed showing the $\underline{F}$-ratio score, the acceptance or rejection of the research hypothesis, and an examination of the means of subgroupings used to determine effects. Hypotheses will be considered in the order presented in Chapter II of primary and subhypotheses. This distinction is made since the

${ }^{1}$ The statistical analysis presented in this chapter was accomplished by CDC 3300 computer, using the Oregon State University Statistical Analysis Program, OSU-03, a statistical model for threefactor analysis of variance. 
primary concern of the study is the effect of Order and Rate of Presentation and their interaction.

Table III indicates the factorial design with experimental observations of the average muscular tension rates measured in volts being supplied for each factorial cell. Since this design is without replication, each entry represents the average for an individual subject rather than an average among several subjects. These data were treated by analysis of variance to determine the main and interaction effects presented by the hypotheses. Table IV reports the results of the analysis of variance.

Hypothesis 1. Sampled muscular tension levels will differ significantly with Order of Presentation.

The Order of Presentation main effect hypothesis has an $\underline{F-r a t i o ~ o f ~} 1.037$ which fails to meet the criterion for significance. The research hypothesis is therefore rejected. A point of interest in examining the respective means for Orders of Presentation (Table V) shows tension levels being highest for the presentation containing speech samples ascending in rate (Order A) and lowest for the presentation having speech samples descending in rate (Order F). This finding differed from the theoretical expectation that Orders of Presentation initiated by compressed speech would yield higher 
TABLE III

SAMPLED MUSCULAR TENSION AVERAGES WITHIN UNREPLICATED FACTORIAL CELLS MEASURED IN VOLTS

\begin{tabular}{|c|c|c|c|c|c|c|c|c|c|c|c|c|c|}
\hline \multirow{3}{*}{\multicolumn{2}{|c|}{ Sex of Listener }} & \multicolumn{12}{|c|}{ Orde $x$ of Presentation } \\
\hline & & \multicolumn{2}{|c|}{ A } & \multicolumn{2}{|c|}{ B } & \multicolumn{2}{|c|}{ C } & \multicolumn{2}{|c|}{$\mathrm{D}$} & \multicolumn{2}{|c|}{$\mathbf{E}$} & \multicolumn{2}{|c|}{ F } \\
\hline & & $\mathbf{M}$ & $\mathbf{F}$ & M & F & $\mathbf{M}$ & $F$ & $\mathbf{M}$ & $F$ & $\mathrm{M}$ & $F$ & M & $F$ \\
\hline \multirow{3}{*}{$\begin{array}{l}\text { Rate of } \\
\text { Presentation }\end{array}$} & Normal $(n)$ & 2.2609 & 2.0455 & 2.6304 & 0.56318 & 0.19509 & 0.3212 & 2.0597 & 0.1804 & 0.9313 & 1.3514 & 0.3303 & 0.2291 \\
\hline & $75 \% \mathrm{n}$ & 2.374 & 1.435 & 3.0163 & 0.47226 & 0.9126 & 1.0159 & 1. 5463 & 0.8544 & 1. 3897 & 1.0102 & 0.3733 & 0.1904 \\
\hline & $50 \% \mathrm{n}$ & 1.8300 & 1. 732 & 2.9919 & 0.4625 & 1. 0448 & 0.9368 & 2.1623 & 0.4732 & 2.6391 & 0.3981 & 0.6052 & 0.3868 \\
\hline
\end{tabular}


TABLE IV

THREE-FACTOR ANALYSIS OF VARIANCE TEST

\begin{tabular}{|c|c|c|c|c|}
\hline $\begin{array}{l}\text { Source of } \\
\text { Variation }\end{array}$ & $\mathrm{df}$ & $\begin{array}{l}\text { Sum of } \\
\text { Squares }\end{array}$ & $\begin{array}{c}\text { Mean } \\
\text { Square }\end{array}$ & $F$ \\
\hline Order & 5 & 10.3690 & 2.0738 & 1.037 \\
\hline Rate & 2 & .2867 & .1433 & .072 \\
\hline Sex & 1 & 6.4050 & 6.4050 & 3.202 \\
\hline Order x Rate & 10 & .8662 & .0866 & .043 \\
\hline Order $x$ Sex & 5 & 6.2336 & 1. 2467 & .623 \\
\hline Rate $x$ Sex & 2 & .4277 & .2138 & .107 \\
\hline Order $x$ Rate $x$ Sex & 10 & 2.1381 & .2138 & .107 \\
\hline Error & 0 & 0 & 2.0000 & \\
\hline Total & 35 & 26.7263 & & \\
\hline
\end{tabular}


TABLE V

MEAN MUSCULAR TENSION LEVELS FOR ORDER OF PRESENTATION

\begin{tabular}{lcccccc}
\hline \hline Order & $\mathrm{A}$ & $\mathrm{B}$ & $\mathrm{C}$ & $\mathrm{D}$ & $\mathrm{E}$ & $\mathrm{F}$ \\
\hline Mean & 1.9462 & 1.6894 & .7461 & 1.2127 & 1.2866 & .3525 \\
\hline \hline
\end{tabular}

tension levels in subjects than those initiated by normal rates.

Hypothesis 2. Sampled muscular tension levels will differ significantly with Rate of Presentation.

The Rate of Presentation main effect hypothesis has an $\underline{F}$-ratio of .072 which, being non-significant, results in the rejection of this hypothesis. An examination of the mean muscular tension levels of subjects for each rate ( $\mathrm{T}$ able $\mathrm{VI}$ ) shows that tensions increased in the expected direction: tension levels increased linearly with compression levels. Although the expected trend was observed, the magnitude of difference was not sufficiently great to claim significance.

\section{TABLE VI}

MEAN MUSCULAR TENSION LEVELS FOR RATE OF PRESENTATION

\begin{tabular}{lccc}
\hline \hline Rate & Normal & $75 \%$ Normal & $50 \%$ Normal \\
\hline Mean & 1.0915 & 1.2159 & 1.3094 \\
\hline \hline
\end{tabular}


Hypothesis.3. Rate of Presentation and Order of Presentation will show significant interaction.

The hypothesis predicting significant interaction between the variables of order and rate must be rejected on the basis of a nonsignificant F-ratio of . 043. Table VII shows the means for the interaction of these variables. It is noted that tension levels ranged from 2. 1532 to 0.2581 with the highest level of tension being shown for Order A at normal speech speed, and the lowest level of tension occurring with Order $\mathrm{C}$ at normal speech speed. Theoretically, it was predicted that tension rates would be highest for Order $F$ at the 378 wpm rate of compression.

Subhypothesis 1. Sampled muscular tension levels will differ significantly between Males and Females.

The main effect hypothesis with regard to Sex of Listener produced an F-ratio of 3.202 showing no significance. The research hypothesis that there are differences between muscular tension levels produced by Males as compared to levels produced by Females is thus rejected, The mean Male muscular action potential $(1.6274)$ is slightly higher than that of Females(. 7838$)$, but not significantly so. 
TABLE VII

MEAN MUSCULAR TENSION LEVELS OCCURRING FOR THE INTERACTION BET WEEN ORDER OF PRESENTATION AND RATE OF PRESENTATION

\begin{tabular}{|c|c|c|c|c|c|c|c|c|c|c|c|c|c|c|c|c|c|c|}
\hline \multirow[b]{3}{*}{ Rate* } & \multicolumn{18}{|c|}{ Order of Presentation } \\
\hline & \multicolumn{3}{|c|}{ A } & \multicolumn{3}{|c|}{ B } & \multicolumn{3}{|c|}{$\mathrm{C}$} & \multicolumn{3}{|c|}{$\mathrm{D}$} & \multicolumn{3}{|c|}{$\mathbf{E}$} & \multicolumn{3}{|c|}{$F$} \\
\hline & 1 & 2 & 3 & 1 & 2 & 3 & 1 & 2 & 3 & 1 & 2 & 3 & 1 & 2 & 3 & 1 & 2 & 3 \\
\hline Means & 2.1532 & 1. 5968 & 1.7810 & 1.5968 & 1.7443 & 1.7292 & .2581 & .3643 & 1.0158 & 1.1200 & 1. 2003 & 1.3177 & 1.1413 & 1.1999 & 1.5186 & .2797 & .2818 & .4960 \\
\hline
\end{tabular}

TABLE VIII

MEAN MUSCULAR TENSION LEVELS FOR INTERACTION BETWEEN ORDER OF PRESENTATION AND SEX OF LISTENER

\begin{tabular}{|c|c|c|c|c|c|c|c|c|c|c|c|c|}
\hline \multirow[b]{3}{*}{ Sex } & \multicolumn{12}{|c|}{ Order of Presentation } \\
\hline & \multicolumn{2}{|c|}{ A } & \multicolumn{2}{|c|}{$\mathrm{B}$} & \multicolumn{2}{|c|}{$\mathrm{G}$} & \multicolumn{2}{|c|}{$\mathrm{D}$} & \multicolumn{2}{|c|}{$\mathbf{E}$} & \multicolumn{2}{|c|}{$\mathrm{F}$} \\
\hline & $\mathbf{M}$ & $\mathbf{F}$ & $M$ & $\mathbf{F}$ & $\mathbf{M}$ & $\mathbf{F}$ & M & F & $\mathbf{M}$ & $\mathbf{F}$ & $\mathbf{M}$ & $F$ \\
\hline Means & 2.1550 & 1.7375 & 2.8795 & .4993 & .7175 & .7746 & 1.9228 & .5027 & 1.6534 & .9199 & .4363 & .2688 \\
\hline
\end{tabular}


Subhypothesis 2. Sampled muscular tension levels will show significant interaction between Order of Presentation and Sex of Listener.

The interaction effect between Order of Presentation and Sex of Listener was found to insignificant with an F-ratio of .623. Table VIII illustrates the respective means for data showing interaction scores between these two factors. The means show a range of 2.8795 to .2688 with highest muscular tension shown by a Male hearing Order $\mathrm{B}$, and the lowest tension level shown by a Female hearing Order F.

Subhypothesis 3. Sampled muscular tension levels will show significant interaction between Rate of Presentation and Sex of Listener.

Rate of Presentation and Sex of Listener was found not to interact significantly. The $\underline{F}$-ratio score was .107 . The means produced by the se interactions are presented in Table IX.

Subhypothesis 4. Sampled muscular tension levels will show significant interaction among the variables of Rate of Presentation, Order of Presentation and Sex of Listener. 
TABLE IX

MEAN MUSCULAR TENSION LEVELS FOR INTERACTIONS

BETWEEN RATE OF PRESENTATION

AND SEX OF LISTENER

\begin{tabular}{l|c|c|c|c|c|c}
\hline & \multicolumn{6}{|c}{ Rate of Presentation } \\
\cline { 2 - 7 } & \multicolumn{2}{|c|}{1} & \multicolumn{2}{c}{2} & \multicolumn{2}{c}{3} \\
\cline { 2 - 7 } $\begin{array}{l}\text { Sex of } \\
\text { Listener }\end{array}$ & $\mathrm{M}$ & $\mathrm{F}$ & $\mathrm{M}$ & $\mathrm{F}$ & $\mathrm{M}$ & $\mathrm{F}$ \\
\hline Means & 1.4013 & .7818 & 1.6020 & .8297 & 1.8789 & .7399 \\
\hline \hline
\end{tabular}

The interaction effect among the three experimental variables yielded an insignificant $\underline{E}$ score of .107 resulting in rejection of this hypothesis. Table $\mathrm{X}$ completes mean presentations by offering a listing of the mean muscular tensions occurring for this hypothesis. Evidence produced by analyzing muscular action potentials for Males and Females exposed to speech varied by Rate and by Order of Presentation shows no significant differences under any experimental conditions. Chapter $\mathrm{V}$ will summarize and interpret the results of this statistical analysis. 
TABLE X

MEAN MUSCULAR TENSION LEVELS FOR INTERACTIONS OF ORDER OF PRESENTATION, SEX OF LISTENER, RATE OF PRESENTATION

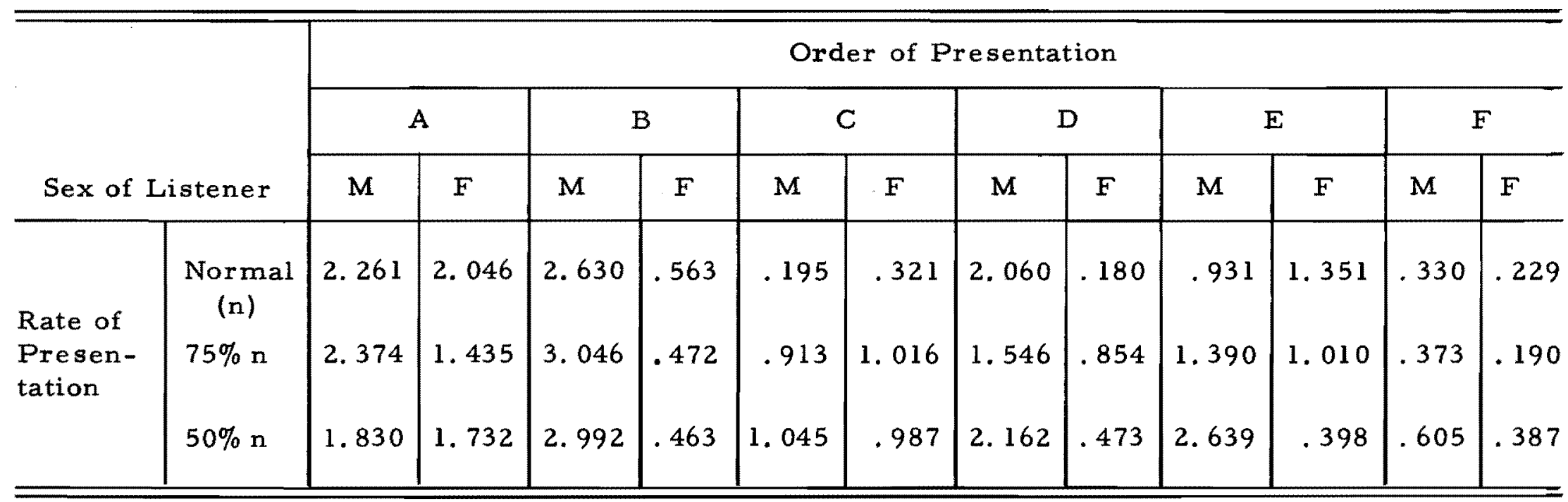




\section{CHAPTER V}

\section{SUMMARY AND CONCLUSIONS}

This final chapter summarizes and interprets the experimental findings of the study. The research hypotheses will be reviewed, relevant results restated, and conclusions drawn. The experimental circuit developed for this study will be discussed. Suggestions for further research will conclude this chapter.

\section{SUMMARY OF THE FINDINGS}

This study has examined muscular tension levels of individuals hearing normal and compressed speech in order to determine the acceptability of compression. "Acceptability" was defined as the individual's ability to receive compression without manifesting tensions of a level that would impair normal functioning. The criterion of acceptability was operationally described as the level of muscular tension produced by an individual while listening to normal speech. Significant differences shown between the amount of tension produced while listening to normal speech and the amount of tension produced while listening to compressed speech.would indicate that the acceptability of compression is in question. This study has quantified the 
muscular tension levels of listeners of normal and compressed speech. The variables manipulated experimentally were Rate of Presentation, Order of Presentation, and Sex of the Listener. Specific rates of speech used were $189 \mathrm{wpm}, 252 \mathrm{wpm}$, and $378 \mathrm{wpm}$. Order of presentation of the three rates was varied into six differing presentation patterns. Both Males and Females were observed. The dependent variable sought was the muscular tension response of the individual. The observation instrument was an electromyograph which recorded muscular activity. Data were analyzed by the statisticalmodel, analysis of variance. The results of the study will be summarized and discussed by examining primary and secondary research hypotheses.

\section{Primary Hypotheses}

Hypothesis 1. Sampled muscular tension levels will differ significantly with Order of Presentation.

Hypothesis 2. Sampled muscular tension levels will differ significantly with Rate of Presentation.

Hypothesis 3. Rate of Presentation and Order of Presentation will show significant interaction.

Evidence produced by this study shows that muscular tension levels are not significantly affected by Order of Presentation, Rate 
of Presentation, or in interactions between Order or Rate. It is inferred that individuals do find compression to be an acceptable mode of presentation based on observations that muscular tension responses are similar in individuals under the conditions of listening to normal and compressed speech. Electromyographic observation of muscular tension showed that individuals respond similarly to compressed and normal speech at rates of 189, 252, and $378 \mathrm{wpm}$. Results of research in comprehension of compression show that speech at the rates of $189 \mathrm{wpm}$ and $252 \mathrm{wpm}$ are within the rate range showing a high degree of comprehension $(11,12,13,22,62,64$, $65,56)$. Based on the observations that muscle tension levels are similar and comprehension is high for the rates of 189 and $252 \mathrm{wpm}$, it seems feasible to use these rates interchangeably. Speech compressed to $378 \mathrm{wpm}$ is found to be acceptable to the listener in terms of muscular response, however, not in terms of comprehension. Research has shown that speech compressed beyond 325 wpm results in significant reduction of comprehension. The feasibility of use of speech at $378 \mathrm{wpm}$ is in question due to loss of comprehension at this rate.

The results of the study differed from the theoretical expectations set forth in the research hypotheses. For instance, speech compressed at 378 wpm was predicted to produce an increase of muscular tension in listeners. The prediction was based on 
observations by Belanger (6) and Murrell (47) who suggest that as task difficulty is increased, tension levels increase. Task difficulty was expected to be highest for the $378 \mathrm{wpm}$ rate since the perception time available to the listener is sharply reduced and comprehension is known to decline $(22,50,62,65)$. Differences were not found in tension levels produced for the $378 \mathrm{wpm}$ rate compared with the 189 and $252 \mathrm{wpm}$ rates. A possible explanation for the absence of increased muscle tensions is that listeners did not find the listening difficult, but rather that they found listening impossible due to their decreased comprehension of content. Lack of motivation to listen for understanding when comprehension declined resulted in reduced muscular tension. This explanation seems feasible from an activation point of view. To initiate an activation analysis some background material will be given on muscular tension and activation. Muscular tension levels are states of contraction or tonus of skeletal muscles. They are excellent indices of activation levels within the individual because as an individual becomes more active, the level of tension in all bodily muscles builds up increasing as alertness increases (66). Woodworth and Schlosberg (66) believe that muscular tonic levels are more than the result of alertness, but are one of the mechanisms involved in producing alertness. Murrell (47) states that individuals have various degrees of activation extending from non-voluntary states of alertness to voluntary 
states of alertness. He believes that a self-arousal system can be activated by the individual when he decides to perform well in a particular task. The auto-arousal system is "cortical activation resulting from stimulation of the reticular formation by the cortex, this stimulation being under voluntary control" (47, p. 430). The condition of auto-arousal would theoretically be manifest in higher tension levels, indicating the individual's preparedness to respond to sensory input (47). Tension, besides being under voluntary control, has optimum values. Optimum values (66) are points at which performance is best, above which tension levels impair performance and below which tension levels are not sufficient for maximum performance.

With this information in mind the lack of high tensions accompanying the high rate of compression might be due to the individual's failure to activate his auto-arousal system. He may perceive the task of listening for comprehension impossible and "resign" himself by lowering his muscular tension response. The fact that comprehension scores decline for this rate indicates that tension levels may not be at optimum values, since performance is seen to be impaired. Therefore, the lack of increased muscular tensions for speech compressed to $378 \mathrm{wpm}$ may be due to the individual viewing the situation as unrewarding as far as comprehension is concerned, thereby reducing his attentiveness to the speech stimuli.". 
An analysis of mean muscular tension in some of the experimental conditions reflects tendencies which differed from theoretical expectations. For example, it was predicted that Order of Presentation initiated by 378 wpm would be more tension producing than Orders initiated by normal speech when in fact the opposite was found. The lack of higher tensions for the presentation initiated by 378 wpm may be due to one of two conditions: the tension levels were the result of the Order of Presentation, or the tension levels were the result of individual differences. The second condition appears to be more likely when the means for interactions between Rate and Order are examined. The individual appears to establish a tension level at the beginning of the speech presentation from which he deviates very little. The greatest variety in scores is shown by comparing individuals, not by comparing tension levels produced by one individual for the three rates. This suggests that there is variety in the general level of tension between individuals; however, this difference is of insignificant magnitude. The design of this study showed no replication of observation within factorial cells. A study having replications might show less individual differences in the reception of compression by averaging a variety of tension levels for each factorial cell.

In summary, an examination of the primary research hypotheses suggests the conclusion that individuals do find some degree of 
compressed speech acceptable in terms of muscular tension levels. Muscular tension levels related to the rates of $189,252,378 \mathrm{wpm}$ as used in this study are well within "acceptability" limits. Further, it appears that the best explanation for the variations observed in muscle tension levels for Order of Presentation and interaction between Order and Rate of Presentation is that individuals generally have different levels of tonus or muscular tension which is in response to individual differences rather than in response to the experimental listening condition. This conclusion is drawn on the basis that after an individual establishes an original tension level, he varies from the level very little in subsequent listening conditions.

\section{Subhypotheses}

Subhypothesis 1. Sampled muscular tension levels will differ significantly between Males and Females.

Subhypothesis 2. Sampled muscular tension levels will show significant interaction between Order of Presentation and Sex of the Listener.

Subhypothesis 3. Sampled muscular tension levels will show significant interaction between Rate of Presentation and Sex of the Listener.

Subhypothesis 4. Sampled muscular tension levels will show 
significant interaction among the variables of Rate of Presentation, Order of Presentation, and Sex of the Listener.

No significant differences were found in muscular tension levels of Males as compared to Females in averaged tension response, in interactions with Order of Presentation, in interactions with Rates of Presentation, or in interactions with Rate and Order of Presentation. Sex as a variable does not significantly affect reception of compression. Males as well as Females find speech rates of 189 wpm, 252 wpm, 378 wpm acceptable from an analysis of muscular tension response.

Statistical analysis of recorded muscle tensions showed that speech at rates of $189 \mathrm{wpm}, 252 \mathrm{wpm}$, and $378 \mathrm{wpm}$, varied by Order of Presentation and received by Male and Female subjects presented no significant difference for main or interaction effects of these variables. The most useful inference drawn from this study is that compressed speech (within the limit of rates tested) can be substituted for normal rates of presentation, where it appears advantageous to do so, without producing detrimental stress upon the listener. This inference is based on the assumption that muscle tension is an adequate index of stress. To the extent that the assumption is valid and since muscular tension levels were found to be similar in each of 
the experimental conditions, it is reasoned that subjects found the stimuli of normal and compressed rates to be equally stressful, and that one can be substituted for the other on the basis of this criterion.

Another important conclusion found from this research beyond the hypotheses is that the electromyographic circuit developed for this study appears to be ideal for investigation of tension levels. The circuit has features which lend ease to the collection of muscle tension data. The features considered are listener comfort, data gathering, data analysis.

Listener comfort is maximized by the circuit in the type of electrode used. Contact surface electrodes were used in lieu of commonly employed needle electrodes. Extraneous noise signals which are picked up by the surface electrodes are cancelled by use of a differential amplifier, thereby maximizing listener comfort without compromising the muscle signal received by the surface electrode.

The process of data gathering was very simple, involving only recording muscle tension activity and the speech signal received by the listener on separate channels of a stereo tape recorder. This necessitated the following equipment: a stereo tape recorder, electrodes, a differential amplifier, a monaural tape recorder, ear phones and a patchcord. During the experiment the speech signal was sent to the listener via headphones and to one channel of the 
stereo tape recorder by a patchcord, Muscle activity was received by the electrodes and carried to the differential amplifier where the signal was purified and amplified. The amplified signal was carried into the other channel of the stereo tape recorder. This resulted in one tape containing the amplified muscle reactions on one track and the speech stimulus on the other. The use of the tape, it is felt, is superior to line graph recordings or oscilloscopic pictures which are used in most electromyographic research, since it offers a concise reproduction of the entire experiment by a tape recording of perfectly correlated muscle responses with speech stimulus presented.

The analysis of the taped muscle tension levels was accomplished by inserting the tape input into a multi-function voltmeter, which automatically sampled and integrated muscle levels. The sampled muscle tension comprised the experimental data for the study. Typically, electromyographic studies have been faced with a problem of how to realistically analyze the amount of muscular tension readings produced through electromyography. Methods employed have been line graphs of muscular tension, and photographs of oscilloscopic displays of muscle tension waves. The method employed in this study has two advantages: first, it allows for a methodical simultaneous sampling and integrating process at equal intervals, and second, the computations are easily obtained and have 
machine accuracy. The first advantage allows time to be saved by use of a voltmeter, because the sampling and computing is accomplished by the machine in one step. Analysis of tension waves on a polygraph would be time consuming and tedious, requiring a measurement step and an integration step. Oscilloscopic photography would entail an intermediary step of taking photographs at set intervals and then transforming the waves into numerical values. A voltmeter analyzes the data directly from the tape recording involving no intermediary computation of wave values. The voltmeter, then, offers ease in data gathering accompanied by machine accuracy which on the basis of time saved is superior to other collection methods.

In summary, the electromyographic circuit developed for this study has been found to be ideal for the investigation of muscle tension. Among the advantages the circuit has are ease in data collection and data analysis and maximal subject comfort.

\section{SUGGESTIONS FOR FURTHER RESEARCH}

This study initiates an approach which determines listener response to compression by psychophysical examination. Psychophysical observation has many potential research uses. Following are some suggested areas for further research which myographically observe listener tension response to compression. 
As indicated in the previous chapter, the design of this study should be replicated using more than one observation per factorial cell. Increasing the number of subjects observed would offer a broader evidence base for the conclusions drawn in the study, and by increasing the degrees of freedom replication would lower required F-ratio levels for significance determination.

A sequel to research in psychophysical acceptability of compressed speech would be a study which examines comprehension of compressed material in conjunction with tension levels. Through observation tension levels which accompany high and low performance in comprehension testing could be determined. Results of the observations could be the determination of tension level ranges which accompany high performance in comprehension. The tension level range may be used as a predictor of performance in comprehending compressed material.

One might test myographically, also, individual response to practice by comparing comprehension test scores and tension scores in order to understand whether tensions are reduced with practicelistening. Myographic and comprehension observations might be gathered for presentations using various degrees of compression, various modes of compression (monotic or dichotic), various exposure times to compression, compression material of different difficulty levels, and for different populations of listeners to 
determine whether any tension differences occur within these situations.

In summary, further research in compression may be motivated to determine the amount of stress felt by the individual in listening situations involving compression. Stress indicators, muscle tension levels, are translators of psychic feeling into somatic activity (1, p. 10), and therefore offer a vehicle for understanding the psychophysical stress-tension phenomenon. Research in compression could use muscle tension levels to determine the feasibility of use of compression in varied listening situations. It is also suggested that other psychophysical testing instruments might be used to determine how the body receives and translates compression. 


\section{REFERENCES}

1. Ax, Albert F. "Goals and Methods of Psychophysiology." Psychophysiology 1:8-25, 1966.

2. Barabasz, Arreed F. "A Study of Recall and Retention of Accelerated Lecture Presentation." The Journal of Communication $18: 283-287,1968$.

3. Bartoshuk, Alexander K. "Electromyographic Gradients as Indicants of Motivation. " Canadian Journal of Psychology 9:215$230,1955$.

4. Bartoshuk, Alexander K. "EMG Gradients and EEG Amplitude during Motivated Listening. " Canadian Journal of Psychology $10: 156-164,1956$.

5. Bartoshuk, Alexander K. "Electromyographic Reactions to Strong Auditory Stimulation as a Function of Alpha Amplitude." Journal of Comparative Physiological Psychology 52:540-545, 1959.

6. Belanger, David. "Muscle 'Gradients' and Higher Mental Processes." Canadian Journal of Psychology 11:113-122, 1957.

7. Berry, R. N. and R. C. Davis. "Muscle Responses and their Relation to Rote Learning. " Journal of Experimental Psychology $55: 188-194,1958$.

8. Calearo, C. and A. Lazzarone. "Speech Intelligibility in Relation to the Speed of Usage." Laryngoscope 67:410-419, 1957.

9. Diehl, Charles, Richard C. White, and Kenneth Burke. "Rate and Communication." Speech Monographs 26:229-232, 1959.

10. Fairbanks, Grant, W. L. Everitt, and R. P. Jaeger. "Method for Time or Frequency Compression-Expansion of Speech." Transaction of The Institute of Radio Engineer 8 , Professional Group on Audio AU2(1). 7-12, 1954. 
11. Fairbanks, Grant, Newman Guttman, and Murray S. Miron. "Auditory Comprehension in Relation to Listening Rate and Selective Verbal Redundancy." Journal of Speech and Hearing Disorders 22:23-32, 1957.

12. Fairbanks, Grant, Newman Guttman, and Murray S. Miron. "Auditory Comprehension of Repeated High Speed Messages." Journal of Speech and Hearing Disorders 22:20-22, 1957.

13. Fairbanks, Grant, Newman Guttman, and Murray S. Miron. "Effects of Time Compression upon the Comprehension of Connected Speech." Journal of Speech and Hearing Disorders 22:10-19, 1957.

14. Fairbanks, Grant and Frank Kodman, Jr. "Word Intelligibility as a Function of Time Compression." Journal of the Acoustical Society of America 29:636-641, 1957.

15. Foulke, Emerson. "A Comparison of Two Methods of Compressing Speech." Paper read at Southeastern Psychological Association, Louisville, Kentucky, March, 1962.

16. Foulke, Emerson. "Comparison of Comprehension of Two Forms of Compressed Speech." Exceptional Children 33:169$173,1966$.

17. Foulke, Emerson. "The Influence of a Reader's Voice and Style of Reading on Comprehension of Time-Compressed Speech." The New Outlook for the Blind 61:65-68, 1967.

18. Foulke, Emerson. "Listening Comprehension as a Function of Word Rate." The Journal of Communication 18:198-206, 1968.

19. Foulke, Emerson. (editor) Proceedings of the Louisville Conference on Time Compressed Speech, October 19-21, 1966. Center for Rate Controlled Recordings, University of Louisville: Louisville, Kentucky, 1967.

20. Foulke, Emerson. "The Retention of Information Presented at an Accelerated Work Rate." International Journal for the Education of the Blind 16:11-15, 1966.

21. Foulke, Emerson. "A Survey of the Acceptability of Rapid Speech." The New Outlook for the Blind 60:261-265, 1966. 
22. Foulke, Emerson, C. H. Amster, C. T. Nolan, and R. H. Bixler. "The Comprehension of Rapid Speech by the Blind." Exceptional Children 29:134-141, 1962.

23. Foulke, Emerson and T. G. Sticht. "Listening Rate Preferences of College Students for Literary Material of Moderate Difficulty." Journal of Auditory Research 6:397-401, 1966.

24. Friedman, Herbert L. and Raymond Johnson. "Compressed Speech: Correlates of Listening Ability." The Journal of Communication 18:207-218, 1968.

25. Garvey, William D. "The Intelligibility of Speeded Speech." Journal of Experimental Psychology 45:102-108, 1953.

26. Gerber, Sanford E. "Dichotic and Diotic Presentation of Speeded Speech. " The Journal of Communication 18:272-282, 1968.

27. Gerber, Sanford E. "Monotic versus Diotic Presentation of Dichotic Speeded Speech." The Journal of Communication 19: $325-332,1969$.

28. Goldhaber, Gerald and Carl Weaver. "Listener Comprehension of Compressed Speech when the Difficulty, Rate of Presentation, and Sex of Listener are Varied." Speech Monographs 35:20-25, 1968.

29. Goldstein, Harry. Reading and Listening Comprehension at Various Rates. Teachers College, Contributions to Education, No. 821, New York: Bureau of Publications, Teachers College, Columbia University, 1940.

30. Hoepfner, Ralph, K. Nihira, and J. P. Guilford, "Intellectual Abilities of Symbolic and Semantic Judgment." Psychological Monographs 80:1-47, 1966.

31. Hogan, D. L. and R. J. Scott. "A Hybrid PDP-1 System for Speech Research. " Digital Equipment Users Society Proceedings, 1963 Annual Meeting 183-191, 1963.

32. Hutton, C. L. A Psychophysical Study of Speech Rate. Doctoral Dissertation. Urbana, Illinois: University of Illinois, 1954. 
33. Hyman, Cohen L. and Joel Brumlik. A Manual of Electroneuromyography. New York: Harper and Row, 1967.

34. Inman, Verne T., H. J. Ralston, J. B. Saunders, B. Feinstein, and E. Wright. "Relation of Human Electromyogram to Muscular Tension." Electroencephalograph and Clinical Neurophysiology 4:187-192, 1952 .

35. Jester, Robert E. and R. M. W. Travers. "Comprehension of Connected Meaningful Discourse as a Function of Rate and Mode of Presentation." Journal of Educational Research 59:297-302, 1966.

36. Jester, Robert E. and R. M. W. Travers. "The Effect of Various Presentational Patterns on the Comprehension of Speeded Speech." American Education Research Journal 4:353-360, 1967.

37. Kurtzock, George H. "The Effects of Time and Frequency Distortion upon Word Intelligibility." Speech Monographs 24:94, 1957.

38. Lippold, O. C. J. "Electromyography." In A Manual of Psychophysical Methods (edited by P. H. Venables, I. Martin) Amsterdam, Holland: North Holland Publishing Company, 1967.

39. Loper, Janis. "An Experimental Study of Some Effects of TimeCompression upon Comprehension and Retention of a Visually Augmented Televised Speech." Dissertational Abstract 27:4370, 1967.

40. Luterman, David M., Oliver Welsh, and Jay Melrose. "Responses of Aged Males to Time-Altered Speech Stimuli. " Journal of Speech and Hearing Research 91:226-230, 1966.

41. McLain, Julie R. "A Comparison of Two Methods of Producing Rapid Speech." International Journal for the Education of the Blind 12:40-42, 1962 .

42. Meucher, H. and H. Hechhausen. "Influence of Mental Activity and Achievement Motivation on Skeletal Muscle Tonus." Perceptual and Motor Skills 14:217-218, 1962.

43. Miller, R. L. "Auditory Tests with Synthetic Vowels." Journal of the Acoustical Society of America 23:632, 1951. 
44. Miller, George A. and J. C. R. Licklider. "The Intelligibility of Interrupted Speech. " Journal of the Acoustical Society of America 22:167-173, 1950.

45. Miron, Murray S. and Eric Brown. "Stimulus Parameters in Speech Compression." The Journal of Communication 18:219$235,1968$.

46. Morris, J. M., G. Brown, and D. B. Lucas. "An Electromyographic Study of the Intrinsic Muscles in the Back of Man." Journal of Anatomy 96:509-520, 1962.

47. Murrell, K. E. "Performance Differences in Continuous Tasks." Acta Psychologica 27:427-435, 1967.

48. Orr, David B. "Note on Thought Rate as a Function of Reading and Listening Rates." Perceptual and Motor Skills 19:874, 1964.

49. Orr, David B. "Self-Pacing Behavior in the Use of TimeCompressed Speech." Journal of Educational Psychology 60: $28-31,1969$.

50. Orr, David B. "Time-Compressed Speech--A Perspective." The Journal of Communication 18:288-292, 1968.

51. Orr, David B. and Herbert L. Friedman. "The Effect of Listening Aids on the Comprehension of Time-Compressed Speech." The Journal of Communication 17:223-227, 1967.

52. Orr, David B. and Herbert L. Friedman. "Effect of Massed Practice on the Comprehension of Time-Compressed Speech." Journal of Educational Psychology 52:601 1, 1968.

53. Orr, David B., Herbert L. Friedman, and Jane Williams. "Trainability of Listening Comprehension of Speeded Discourse." Journal of Educational Psychology 56:148-156, 1965.

54. Pestalozzi, G. and I. Shore. "Clinical Evaluation of Presbyacusis on the Basis of Tests of Auditory Function." Laryngoscope 65:1136-1163, 1955.

55. Posner, M. I. and R. F. Mitchell. "Chronometric Analysis of Classification." Psychological Review 74:392-409, 1967. 
56. Reid, Ronald H. "Grammatical Complexity and Comprehension of Compressed Speech. "The Journal of Communication 18: 236-242, 1968 .

57. Reynolds, Larry T. Auditory Comprehension of Time-Compressed Material. Master's Thesis. Ogden, Utah: University of Utah, 1966.

58. Scott, Robert J. "Time Adjustment in Speech Synthesis." Journal of the Acoustical Society of America 41:60-65, 1967.

59. Shriner, T. H. "Effects of Time-Compressed Speech, Children's Identification Accuracy and Latency Measures. " Journal of Experimental Child Psychology 7:532-540, 1969.

60. Sticht, Thomas G. "Some Relationships of Mental Aptitude, Reading Ability, and Listening Ability Using Normal and TimeCompressed Speech." The Journal of Communication 18:243$258,1968$.

61. Voor, John B. The Effect of Practice Upon Comprehension of Time-Compressed Speech. Master's Thesis. Louisville, Kentucky: University of Louisville, 1961.

62. Voor, John B. and J. M. Miller. "The Effect of Practice Upon the Comprehension of Time-Compressed Speech. " Speech Monographs 32:452-454, 1965.

63. Welford, A. T. "Arousal, Channel-Capacity and Decision." Nature 194:365-366, 1962.

64. Wood, David C. "Comprehension of Compressed Speech by Elementary School Children." Dissertational Abstracts 27:336$337,1966$.

65. Woodcock, N. W. and Charlotte R. Clark. "Comprehension of a Narrative Passage by Elementary School Children as a Function of Listening Rate, Retention Period, and I. Q." The Journal of Communication 18:259-271, 1968.

66. Woodworth, Robert and Harold Schlosburg. Experimental Psychology. New York: Holt and Company, 1955.

67. Zemlin, W. R. "The Difficulty of Listening to Time-Compressed Speech." Journal of Speech and Hearing Research 11: $875-881,1968$. 
APPENDICES 
APPENDIX A

FORM SENT TO STUDENTS COMPOSED OF INVITATION TO PARTICIPATE, QUESTIONNAIRE, AND HUMAN RELEASE FORM

NAME

Through a scientific process of sample selection which is designed to insure representativeness, you have been selected to participate in an experiment. It is important in order to maintain proper experimental control to have your participation if it is at all possible. The experiment will involve approximately one hour of your time, and concerns muscular tension produced while listening to speech. You will find the participation interesting, and if you participate, the results of the study will be available to you.

Please respond to the following questions by checking the appropriate blank. This data is necessary to insure homogeneity of subjects.

1. I am __, am not___, able to participate.

2. I am between the ages of:

under 18

$18-20$
21-25

over 25 
3. I have , have not , heard Ralph Nichols' listening tape on the skills of good listening.

4. I have , have not , heard compressed speech.

5. I am_, am not - taking any medication which serves as a pain-killer (other than aspirin compounds) or a muscle relaxer. If you indicated that you are taking some medication, please state what it is

6. I have lived in the United States for years. (how many years)

7. I would be available for one hour at any of the following hours: for the weeks of $\operatorname{Jan} 19-24,26-31$ :

(Please circle the appropriate squares)

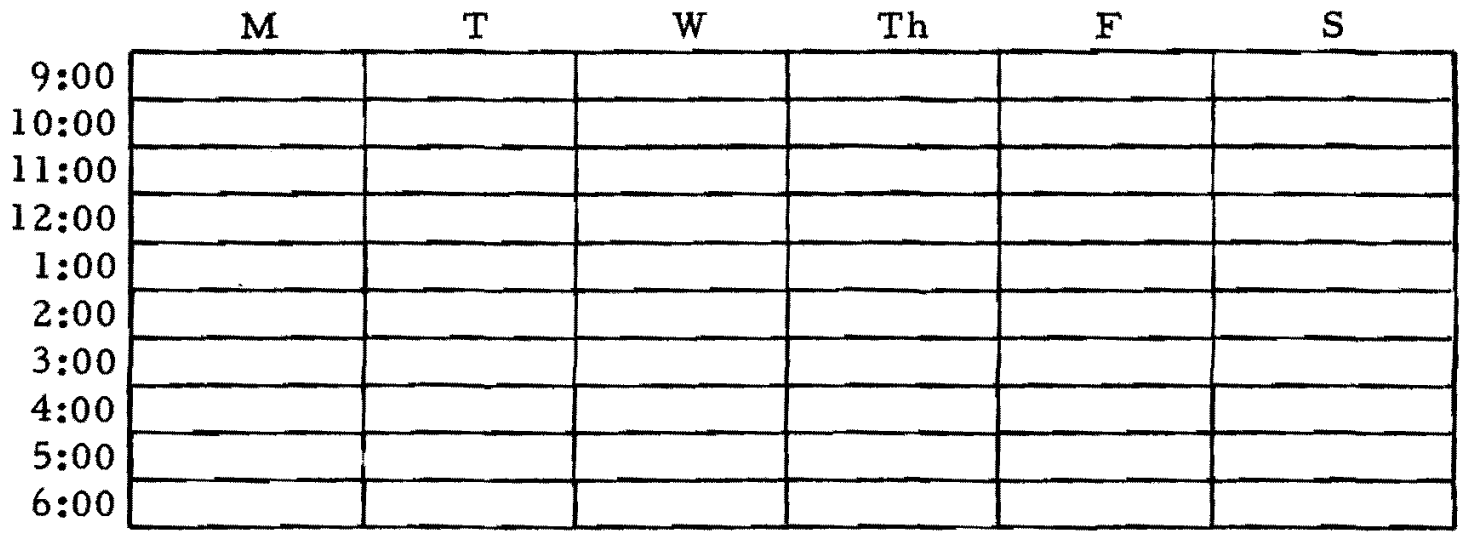

8. My name is

Address phone \#

Thank you for your cooperation and within the next few days I will confirm a time with you for the experiment. 
HUMAN SUBJECT RELEASE FORM

I, (print full name)

freely offer myself as a subject for an empirical study under the sponsorship of the PSU Speech Communication Laboratory. I have been informed to my satisfaction about the procedures of the study, and $I$ understand that any information regarding my performance or regarding information about myself which I provide will be treated confidentially and that publication of such information will conceal my identity.

Date

Date of Birth
Signature

If subject is under 21 years of age, this release must be countersigned by a parent or authorized guardian. 


\section{APPENDIX B \\ THE TEN WORST LISTENING FAULTS \\ BY RALPH NICHOLS}

Therefore in the few moments remaining me I (wish) would like to just ennumerate and comment only very briefly upon what seem to me to be the ten worst listening habits of the American people. For in each case if we would build the counterpart skill we could become tremendously proficient in this matter of learning through our ears.

Bad listening habit number one is calling the subject uninteresting. The bad listener does it almost every time as soon as the chairman announces the topic or the bad listener reads it on a printed program. He says to himself:

Oh-h-h for heaven sake--that old chestnut again? We've been 'round and around this matter of communication 'til I'm sick of it. He couldn't possibly have anything to say that I can use; so, I guess I'll worry about that car of mine, am I going to trade it in this year or wait another twelve months?

Off he goes on a mental tangent, because the subject is too dry to hold any worth for him.

The good listener starts at the same point, but he moves quickly to a different position. He says at the first of the speech: 
Gee, this sounds awful. The same old topic. It's funny that they couldn't get Glen Cassanova or somebody interesting in here for a speech. But now wait a minute, inasmuch as I am trapped anyhow, uh, I might as well tune this old professor in to see if he has anything to say that I can use.

The key to good listening in the first instance is that little three letter word "use." The good listener is a sifter, a screener, a winnower of the wheat from the shaft. He is always hunting for something practical or worthwhile to stash away in the back part of his brain, and put to work for his own selfish welfare in the months ahead. We acknowledge the selfish character of it. We say to our Freshman trainee group again and again: "Be just as selfish as you can be when you listen. Always hunt for the practical or the worthwhile, it will help you individually in the months and the years ahead of you." E. K. Chesterton put it all beautifully in a nutshell when he said, "In all this world there is no such thing as an uninteresting subject, there are only uninteresting people. "

Bad listening habit number two is criticizing the speaker's person or delivery. This, for the bad listener becomes almost an indoor pastime. As soon as the man stands up after being introduced, the bad listener says to himself:

What a character--can you believe they'd pay a fee to bring this man in here. Why he barks, and snorts and coughs! I've never seen such an inept specimen on a speech platform before in my life. Apparently nobody ever told him not to read all the time, or keep his hands out of his pockets once in while. 
On and on you could go, you could find a hundred mental picks to take at any speaker who stands before you and the bad listener becomes greatly preoccupied with this very practice.

The good listener starts up again at the same point but he gets to a different position. At the beginning of each talk he's likely to say:

Gee, this fellow's inept. I don't know when I've seen such a poor specimen on a speech platform. But wait a minute! He knows some chemistry I don't know or he wouldn't be holding the position he holds, and this is a required course. I've got to earn five credits in this stuff, somehow or another, I'd better pick this man's brains if it kills me. I'll spend every erg of energy I have inside me to get what he knows that I don't know.

And he begins to bear down on the content of the speech instead of the clothing in which it comes garbed. And you know, after a few moments go by, pretty soon all the (speakner) speaker (uh) delivery weaknesses disappear, and the listener becomes completely oblivious to them. Oh, this is significant! Let me illustrate it. Suppose a janitor stepped through that double doorway right now, screamed at us in broken, profane vulgar English: "Get the heck out of here the building's on fire!" You and I would not all lean back in our respective chairs and say: "Please sir, will you not couch that admonition in better rhetoric before we follow you?" We would be very glad to rush pell-mell out of here, as you well know. And this is my point, the message is always ten times as important as the 
delivery of it. If we would become good listeners we must bare down on content, and forget the clothing in which that content is dressed.

Bad listening habit number three is getting overstimulated. I feel like an authority on this one, for as far as I can look backward across my life, I've been overstimulated personally about something. Speakers get me so excited, I can't sit still. Very seldom when I'm in an audience does a speaker talk more than three of four minutes before I want to throw a hand up and challenge him on something. (Uh-h) If it is too formal to break right in on him in that way, many times I'11 sit there and try to compose the dirtiest and meanest, most embarrassing question the human brain can contrive. Oh, you can get some bad ones for any speaker, using this old technique of asking, "Have you stopped beating your mother yet?" (uh) He's impaled whether he says yes or no to that one. You can use that on any topic he may be discussing and really cause him some embarrassment at the end of his talk--if that doesn't just fit, many times perhaps knowing a bit of evidence to contradict something he has reported. I will sit there and build myself a great five minute rebuttal effort. By the end of the talk many times, I have jumped to my feet, got permission from the chairman, hurled my embarrassing question at the speaker or made my great rebuttal effort, only to find him looking at me in complete wonderment and saying: "Well, 
Nichols, didn't you hear what I went on to say when I explained that so-and-so was also true?" I hadn't. My listening efficiency drops to a zero per cent level every time I get over-stimulated; and that's most of the time. Oh, this is an important business. We think that it is so important that in big bold letters at the top of the blackboard in every classroom where we teach listening back home, we put this maxim: "Withhold evaluation until comprehension is complete." And if we think they can't read those words, we put up there: "Hear the man out, before you judge him." Oh, this is important! Americans are a nation of snap-judgment making. The first time we are introduced to a man and shake hands with him, we are likely to say: "This man is a nincompoop," or (uh) likely to say: "What a fireball. This fellow has something." (uh) And many times we guess wrong. Actualiy, if we could be right fifty-one or fifty-two per cent of the time, I suppose we could all be millionaires. We only bat about five hundred in this league of guessing what the man is going to say before we really understand it. We think it very critical to learn to withhold evaluation until comprehension is complete.

Bad listening habit number four is listening only for facts. I suppose one would go a long way in Portland to round up a few hundred people with as much respect for facts as you folks have. I used to haye a lot of respect for facts, too, but I have been losing a lot of mine. Let me tell you why. I asked the hundred poorest 
listeners this question... [pause]".. performance you gave the other day, I said, what do you concentrate on primarily when you listen?" One hundred out of one hundred replied with pride, (they didn't know they had had the lowest scores in the whole freshman population): "When we listen, we listen for the facts." The truth was they got a few, garbled a shocking number, and completely lost the bulk of them. I then asked the one hundred best listeners what they concentrated on when they listened. Ninety-seven out of one hundred said rather timidly: "Well, when we listen, we try to get the main ideas out of it." "What do you mean?" I asked. "Well, in every talk there is always a generalization of some kind. It may be called a principle, or a precept, or a concept, and we try to get the general drift of the discourse." We pursued this with fanatic interest. And, the father we chased this facet of good listening, the more convinced we become that if you want to be a good listener you have to be an idea-listener. For these idea-listeners use these generalizations or principles as connecting threads to give sense and system to the whole discourse. And, after forty-eight hours had past, they had more facts appended to their connecting threads than the cataloguers and spongers of facts had been able to retain on the other hand.

Bad listening habit number five is trying to make an outline out of everything. This is a curious business. One hundred out of 
one hundred bad listeners thought that outlining and note-taking were synonyms. When I asked them what they did for note-taking, they said: "Build an outline, of course." Well, there is nothing wrong with outlining a talk, I think, if the speaker is following an outline pattern for organization--I'll even concede that I think he should be. But between this noon and the day they lay you and me in our respective caskets for eternity, I doubt that more than half the speeches we are going to hear are going to be given by speakers following a careful outlined pattern of presentation. And one of the most frustrating things of our culture is to try to outline the unoutlinable! I've watched students do this hour after hour, and always the student when he's stuck becomes impressed with symmetry. (uh) Perhaps he has a sheet of notebook paper and he gets everything exactly spaced upon it: All the margins are perfect; the coordinating and subordinating (sy) symbols are beautifully arranged; the indentation margins are exactly right: And, after each symbol in his notebook, he writes the meaningless jargon. Two months later trying to review these notes, trying to get ready for the final examination, almost all the review period is spent by the student saying to himself: "What in thunder was I thinking about when I wrote that in there, anyhow?" Oh, this is fruitless business! We asked the (wa) one hundred (uh) best listeners what they did for note-taking, and they said: "It all depends on the speaker, of course." "What do you mean by that?" 
Well, (uh) we don't do anything in the way of note-taking for three or four minutes 'til we see what we are in for. If the man is carefully organized we might outline him, if not, there are other ways of taking good notes. You can get good notes on people who are completely unorganized, or even disorganized.

On and on they went, talking about the Pracey Method, the Abstract Method, the Annotation System, the (uh) Fact-VersusPrinciple System, all this became important, and there is a great principle at stake here: If you are an avid note-taker, always be a flexible note-taker and adjust your style of taking notes to the organizational pattern the speaker is following, or the absence of any at all.

Bad listening habit number six is faking attention to the speaker. For many years as a schoolteacher I would look out over a classroom and feel I was going over real well if I see most of my students looking at me from this pose. (uh) Particularly, if the girls in the first six rows were sitting looking up at me, I was inclined to make this mental note: "Look at this, professor, (uh) you are going over very well today. They all have you tuned in. "We now know that one of the surest indices to inattention in our whole culture is this pose on the part of the listener. Having paid the speaker the overt courtesy of appearing to tune him in, this man now feels conscious free to take off in one of a thousand mental tangents: And that is usually precisely where he has gone. If you ever look 
out across an audience yourself and see the bulk of your listeners looking up at you from this position, for heaven sakes, stop short in your discourse, tell everybody to stand up and do some calisthenics to get the blood circulating again. Good listening is not relaxed and passive at all. It's characterized by a slightly increased beating of the heart, a quicker circulation of blood, a small rise in bodily temperature. The best meaning of the word attention is a collection of tensions inside the listener. Tensions that can be resolved only by getting some facts or ideas that the speaker in trying to convey. It's energy burning and energy consuming, it's dynamic and constructive, this matter of listening well.

Bad listening habit number seven is tolerating or creating distractions. This one is so obvious on the face of it that I will not elaborate it, for my time is flying.

Bad listening habit number eight is the avoiding of difficult and expository presentations. This one is deeply critical. I asked the hundred best listeners about their radio and (uh) TV habits, and found that they had heard a great variety of them. I asked the hundred worst and found that they were authorities on three programs: "Bob Hope, "Red Skeleton, " and the "Lone Ranger." They had never in their lives sat clear through the "Chicago Round Table," "Town Meeting of the Air," "Meet the Press," "See It Now," "Invitation (Learning) to Learning," or "You Are There." The good listeners had sat through 
these more educational type programs many times. You take a youngster who has never heard anything (uh) more difficult than Bob Hope's program, and put him in an auditorium with three hundred other freshmen. Trot out the best Professor of Biochemistry on your faculty and let him start a lecture. He can't talk three sentences before this Bob Hope type listener is saying to himself: "Geez, what this guy talking 'bout: I don't get this a'tall." He's over his head and he knows it. At the end of the first class hour, he beats it for the admissions office, cancels that course and enrolls in one maybe in Economics and it's just about as rough over there. (uh) This youngster is over his depth and he washes right out of college. Is it important? For every two freshmen enrolling on the campuses of our colleges and universities of America today, one washes out before the end of the Sophomore year. Most of the time before the end of the freshman year. At the other end of most of our curriculums, for every young man we can hand a four-year degree there are two employees standing there bidding for his services. Fifty per cent mortality on the intake and we meet half the demand for the trained manpower on the outgo. Ah, I get worried about this. I don't know how long we can stay in competition with a nation like Russia(uh) when we continue to lose one-half the possible trained brain power in our nation. I don't think they lose anything like fifty per cent of their possible trained manpower over there. If I could 
have my way about it, (Heaven knows I won't have. I have practically no influence in this world even in my own house.) I would require every school teacher, in every grade level, in every course being taught, to teach at least ten minutes of listening every week. I would ask her to announce this as signment on Monday and pull it off on Friday. Come Friday, I would ask her to give to her class ten minutes of the toughest, most technical, expository material that they had ever heard in their lives up to that moment, and, immediately upon its termination to subject the group to a comprehension test over its content. I'd want her to record the scores and upon a bulletin board of some kind at the front of the room and keep track. Oh, I'm just confident that if we could subject our selves and our young people to repeated difficult listening experiences we wouldn't have fifty per cent mortality at the university freshman level. I always get heated about this, perhaps overly so.

Bad listening habit number nine is letting emotion laden words throw us out of tune with the speaker. It is a curious fact that a single word may have such an emotion load on it, that it will cause some listener to tune the speaker right out. Now I don't know what words throw you, but we've pinned down a few words that are problem makers, for instance, such words as: mother-in-law does it to some people, landlord, landlady, automation to unionize workers, clerk I discovered a year or so ago is a fighting word. I was 
talking down at Lincoln, Nebraska, to a Retail Sales Convention, and I kept saying: "You clerks know what I mean--you clerks have experienced this." I saw some frozen faces out there, but I didn't realize how badly my faux pas had been. At the end of my talk five women came right up in mass and said: "We are not clerks!"

I said: "Oh, (we) well, what are you?" "We are retail Sales Personnel," they said, "or you may call us Sales' Ladies if you like."

That word "clerk" is apparently a fighting word. I've wiped it out of my vocabulary. (uh) The word Peckerwood down in Texas, or the word Red-neck in Louisiana, or (uh) (uh) such words as (uh) sometimes Harry Truman, or Sherman Adams (uh) make some listener to tune the speaker right out. Oh, this is silly business--to let the symbol for something to stand between us and learning. Yet, some words have such emtional loads in them that they cause the listener to tune the speaker right out. I wish that we could have a PhD study in some College of Education identifying the one hundred greatest word barriers to learning in our language. I wish I know what they were. If we knew, we could graduate them, lay them out in the open, discuss them, and get them behind us.

Bad listening habit number ten is the most important of the ten. It's a little tricky and you will have to tune me in or you may miss it. It's wasting the differential between speech-speed and thought-speed. 
On the average in America we talk 125 words per minute. But put a man in front of an audience and ask him to talk informatively, and he slows down to exactly one hundred words per minute. How fast do people listen? Or, to put the question better, how many words a minute do people think at easy cruising speed if all their thoughts were measurable in words per minute as they listen? And the answer is from all the kinds of research we have been doing on this that easycruising speed for an audience of any size will run between 400 and 500 words thought-speed per moment. Now this differential between speech-speed and thought-speed is a snare, a pitfall, and a delusion. It's a breeder of false security, and a breeder of mental tangents. What actually happens of course is that the listener tunes the speaker in just as you have been doing to me all through this period for about ten seconds, note what he is saying, think a quick circle around it in order to make sure you are not going to miss anything, and then you take off on a mental tangent for about fifty seconds. You worry about your car, your secretary, your wife, your grocery bill or something. And again in ten quick seconds you can find out what the speaker is talking about, decided that it is all old hat, think a quick circle around it for security sake and out you go for another fifty second holiday. You are out for fifty, in for ten; out for fifty, in for ten; out for fifty, in for ten. Really, it wouldn't be so bad if you always came back for the ten. But sooner or later, 
on one of these mental tangents you become too deeply engrossed to leave it. Now at your age levels I don't know just what this one would be. But I think I have a feeling as to what it is in the minds of the typical college male. If he's an engineer listening to a professor, he may tune the professor in who's explaining on the slide rule how to multiply two digit numbers, and he says:

Ah, that old goat, stalling again, I learned that when I was a junior in high school, and he's been through it twelve times in this course. I'll worry about that soft tire on my Ford when I parked it in the lot this morning. If that thing's clear flat at the end of the period, am I going to try to change it or catch a ride with someone else over to the other campus.

He's out fifty seconds and then he tunes the professor in and in ten second he can find that the man is now dividing (uh) two digit numbers on the slide rule. Out he goes quickly on the worry about the chemistry test coming up Thursday morning. He's in and out several times on these personal worries, and then finally a very dramatic thought comes to his mind.

"Which woman am I going to call for a date Saturday night?" he thinks,

Shall I take Susan out again? She's plump, and jolly; she's alot of fun, I've had her out several times. You can always have a good time out with Susan. Best of all she fixes something to eat usually at the end of the evening. That's good, too, it saves some money.

He revels in this idea of another night out (uh) with Susan for awhile. Then, a very dramatic thought hits his cortical centers. 
Wonder if I can get a date with that Martha something-orother I don't know her last name--that female who transferred in here, I think it was from Hammond. Gee, she's in my literature class. I had never seen such a tall, sinuous, glamorous creature in my life. Why, when that woman walks it is just like watching a snake crawl.

And this lad is off on a mental tangent from which there is no return! The next thing he hears is the bell at the end of the hour. And, when he hears the bell ring, he hears the old professor say: "Remember when you take cube root on a slide rule.. "

"Cube root! How do you take cube root?" In panic he grabs some mate going out the back door and says: "What's with this fellow? How do you take cube root on a slide rule?" He doesn't know either--he's been out on another mental tangent. And this is why we actually operate at a twenty-five per cent level efficiency when we listen. But if you can listen four times faster than I can talk, and I am sure you can--I've tried to talk $200 \mathrm{wpm}$ this afternoon with you:folks for two reasons: one, I wanted to cover more material; and two, I wanted to eat up a little of the differential between my poor speech-speed and your tremendous thought-speed. But it hasn't done me much good. The average thought-speed in this audience, in this room today will run just about $800 \mathrm{wpm}$. So even if I got to $200 \mathrm{wpm}$, you wanted to go somewhere four times faster than I could possibly travel. This thing is a liability without training, but it should be the most precious thing we own. If you can think 
four times faster than I can talk, it ought to be a source of tremendous power and strength to you. You ought to be able to hear everything that a speaker says, note what he carefully avoids saying. You ought to be able to identify the weight of the evidence he uses for building his points. You ought to be (uh) able to listen between the lines as well. Actually, this process of coverting what appears to be a liability into an asset is the heart of listening training wherever you find it most successfully operating in America today.

What we must learn to do automatically when we listen is to practice three mental ingredients of concentration: one, anticipate what the man's next point is going to be. If you guess right you are a winner. It comes to your brain centers once when you guess it, a second time when he comes along and builds (builds) it. If you guess wrong, you are still a winner. You guess it is going to be "z," it turns out to be "a," what do you do? Automatically, you compare "z" with "a" and you begin to apply the oldest law of learning in the books, which is we learn best by contrast and comparison. This is the one wager the listener can never lose. He's always the winner if he will run ahead mentally and try to guess the man's next point. The second ingredient of good listening is identifying the man's evidence. What does he use to support his points? There are only three or four ways of point support that are commonly used and to be sophisticated in this matter of their identification is very important. 
Finally and most importantly, if we would become good concentrated listeners, we should throw in mental recapitulations as we listen about every four minutes. In four seconds time at your tremendous thought speed you can summarize all the highlights of my discourse in four minutes or five minutes of speech time. A half dozen of these mental recapitulations interspersed throughout a thirty or forty minutes talk will easily double our understanding and ability to retain the content of that talk. Is this important to you business people? Oh, I think it is of tremendous importance! We are learning we can no longer afford the luxury of a bad listener on our payrolls. One bad listener can eat up all the profits that the rest of us can possibly create.

It is a matter of immense satisfaction to me that the greatest teacher who ever lived, Christ himself, had something to say about this process: At the end of one of his best sermons reported the fourth chapter of Mark twenty-third and twenty-fourth verses, Christ said to a large congregation before him: "If any man has ears to hear, let him hear. With what measure ye meet, it shall be measured to you, and unto you who hear, shall more be given."

Which summarizes pretty well the thought I would like to leave in your minds. 


\section{APPENDIX C}

NICHOLS' COMPREHENSION TEST

Name

1. Recall as many of the bad listening faults as you can.

2. The purpose of part two is to measure the feelings you had during this experiment. In responding to the following items, please make your judgments on the basis of what impressions you actually had. Following is a series of bipolar adjectives, separated by seven blank spaces. If you feel that the concept being looked at is very closely related to one end of the scale, you should place your check mark as follows:

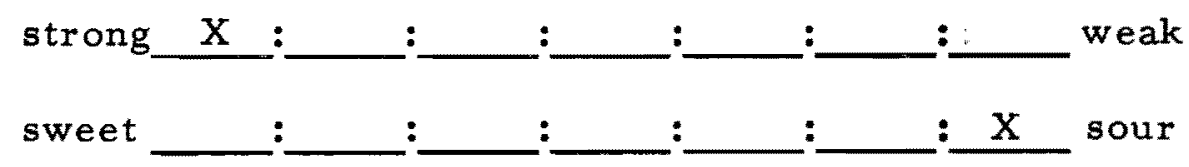

If the concept seems quite closely related to one or the other end of the scale (but not extremely), you should place your check mark as follows: 


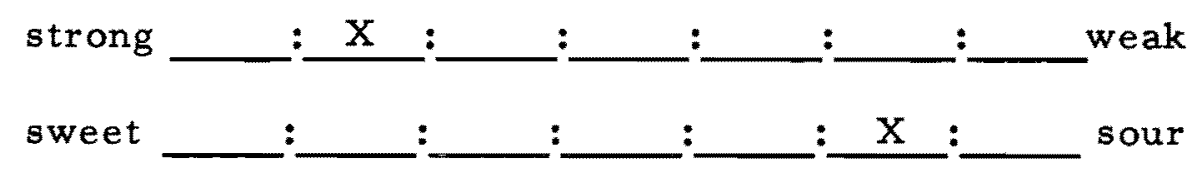

If the concept seems only slightly related to one side as opposed to the other side (but is not really neutral), then you should place your check mark as follows:

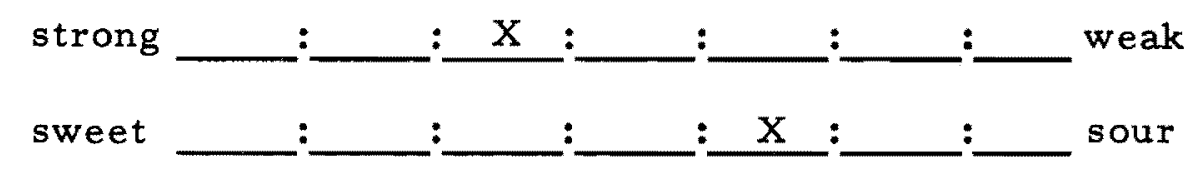

The direction toward which you check, of course, depends upon which of the two ends of the scale seems most characteristic of the thing that you are judging. If you consider the concept neutral on the scale, both sides of the scale equally associated with the concept, then you should place your check mark in the middle space:

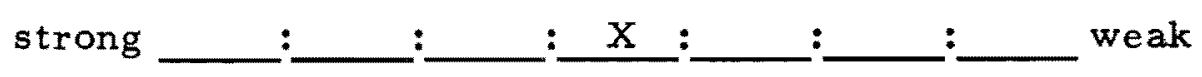

IMPORTANT: (1) Place your check marks in the middle of the spaces and not on the boundaries.

(2) Check every scale for every concept--do not omit any.

(3) Never put more than one check mark in a single scale. 


\section{IMPRESSION DURING THE EXPERIMENT}
a. tensed
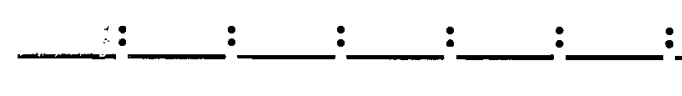 relaxed
b. stressed
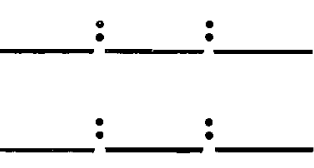
: calm
c. bored
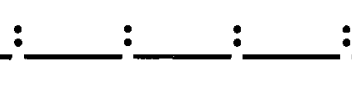 : interested
d. sleepy

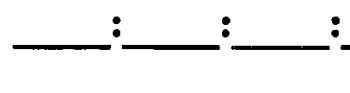 : : awake
e. alert
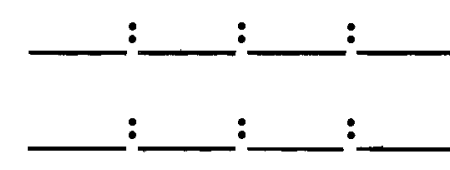 :_____ dull
f. fast : :______ slow
g. pleasing

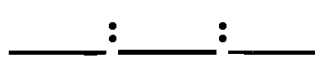 : annoying
h. active

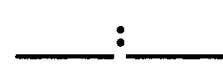 : : : passive
i. happy
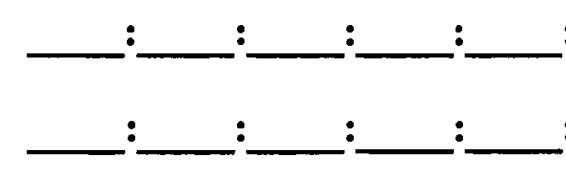 : sad
j. awful $:$ : nice

3. Could you understand what was being said in each of the speech samples? yes no

If you responded no, which tape was difficult to understand? 1 : 2 : 3

4. Are there any other impressions you had while listening that you would like to report? 